\title{
Market Power and Price Movements over the Business Cycle*
}

by

\author{
Bart J. Wilson \\ Interdisciplinary Center for Economic Science \\ George Mason University \\ 4400 University Boulevard, MSN 1B2 \\ Fairfax, VA 22030 \\ bwilson3@gmu.edu
}

\author{
Stanley S. Reynolds \\ Department of Economics \\ University of Arizona \\ P.O. Box 210108, McClelland Hall 401 \\ Tucson, AZ 85721 \\ reynolds@eller.arizona.edu
}

August 2003

\section{JEL Classification: L1, E3}

Abstract: This paper develops and tests implications of an oligopoly-pricing model. The model predicts that during a demand expansion the short run competitive price is a pure strategy Nash equilibrium, but in a recession firms set prices above the competitive price. Thus, price markups over the competitive price are countercyclical. Prices set during a recession are more variable than prices set in expansions, because firms employ mixed strategy pricing in recessions. The empirical analysis utilizes Hamilton's time series switching regime filter to test the predictions of the model. Fourteen out of fifteen industries have fluctuations consistent with this oligopolypricing model.

\footnotetext{
*Wilson acknowledges research support from the John M. Olin Foundation and the National Science Foundation. We thank the Editor and an anonymous referee for comments that have improved the paper. Doc Ghose, James Hamilton, Joe Harrington, Mark Walker, and John Wooders also provided helpful suggestions, as have seminar participants at the University of Arizona, the University of Houston, Johns Hopkins University, the University of Kansas, the University of Toronto, and Virginia Polytechnic Institute and State University.
} 


\section{Introduction}

In this paper we examine price variation in manufacturing industries over the business cycle. This study is motivated by the hypothesis that firms with market power may have incentives to exercise this power differentially over the business cycle. Such differential exercise of market power could exacerbate business cycle fluctuations relative to what would occur in the absence of market power.

Our point of departure is a model of oligopoly investment and pricing that has implications for variations in prices and industry efficiency over the business cycle. This model emphasizes the role of long run production capacity investments that must be made before demand conditions are known. After capacity investments are made, firms learn about the level of product demand and choose prices. The pricing incentives for firms differ depending on the level of demand. If demand is high, then the short run competitive (market clearing) price is a pure strategy Nash equilibrium. However, if demand is low, then capacity constrained firms have an incentive to deviate from the short run competitive price; the typical result is that firms adopt mixed strategies that yield prices above the short run competitive price and that generate excess production capacity. These results are developed in detail in Reynolds and Wilson (2000). We refer to this as a non-collusive oligopoly model to distinguish it from collusive theories of oligopoly behavior over the business cycle.

This non-collusive model predicts that output prices are procyclical, as do many other theories. The key prediction that we empirically examine is that output price changes will have greater variance during low demand periods than during high demand periods. ${ }^{1}$ We search for this differential variance of price changes over the business cycle using a version of time series switching regime filter developed by Hamilton (1989). We estimate this model for each of seventeen manufacturing industries at the two- and three-digit Standard Industrial Classification (SIC) level.

This prediction on business cycle price variation is not unique to this non-collusive model. Staiger and Wolak (1992) formulate a model with demand uncertainty in which firms invest in production capacity and set output prices, as we do. They examine optimal collusion in infinitely repeated games. Staiger and Wolak point out that price-cutting and market-share instability can emerge during demand downturns in their optimal collusion model when the industry is relatively ineffective in maintaining collusion. If we find differential variance of price changes over the business cycle in the data then this could be accounted for by an optimal 
collusion model such as Staiger and Wolak (1992) or by a non-collusive model similar to ours. In either case, a model that provides this variance prediction has the following features: there is demand uncertainty, firms have market power, firms have production capacity constraints, and firms set prices. We might add that if non-collusive models of market power are capable of explaining key empirical regularities, then analysts may not need to turn to relatively more complicated optimal collusion models of behavior over the business cycle.

The paper is organized as follows. Section II provides background on the exercise of market power over the business cycle. In Section III we formulate and analyze a dynamic model in which demand alternates stochastically between expansionary and contractionary phases. We show that ex ante capacity investments coupled with ex post price setting lead to price variation over the business cycle. This formulation provides the structure for our empirical tests. In Section IV we explain the estimation approach, the time series data, and the empirical results. Concluding remarks appear in Section V.

\section{Background on Market Power over the Business Cycle}

Studies by Greenwald et al. (1984), Gottfries (1991), Klemperer (1995), and Chevalier and Scharfstein (1996) have emphasized the role of capital-market imperfections in price fluctuations over the business cycle. When capital-market imperfections exist, the incentives for firms to make investments may be reduced because firms may not reap the profits associated with the investment. One form of investment is a low price that builds a firm's market share by attracting more customers in the future. During a recession, firms may raise prices, forgoing any attempt to raise future market share, because the probability of default is high. Chevalier and Scharfstein (1996) find support for this hypothesis in data drawn from the supermarket industry.

Another strand of the literature has emphasized the role of collusion. Rotemberg and Saloner (1986), Rotemberg and Woodford (1991, 1992) and Bagwell and Staiger (1997) show that a firm participating in a collusive group may have more incentive to defect during a boom period, because the short-term gains from defection are relatively large. Thus, an optimal collusive mechanism may involve lower prices (or markups over marginal cost) during booms than during recessions, in order to eliminate the incentive to defect. Bagwell and Staiger (1997) show that this pattern of countercyclical pricing (or markups) becomes less likely as demand shocks become more positively correlated. ${ }^{2}$

Domowitz, Hubbard, and Petersen (1987) examine the empirical evidence on cyclical 
responses of prices and price-cost margins. With a panel data set of industries at the four-digit SIC level spanning 1958-1981, they find that more concentrated industries have more procyclical margins. As they note, these estimates may be biased upward (downward) if marginal cost is greater (less) than measured average variable cost. Consistent with the Rotemberg and Saloner predictions, Domowitz et al. further find that industries with high price-cost margins have more countercyclical price movements. However, Domowitz et al. use industry-level changes in capacity utilization as a proxy for business cycle movements. Low capacity utilization at the industry level may simply be a result of high prices, rather than the result of a downward shift in demand. Bresnahan (1989) also points out the limitations of cross-industry comparisons of competition when assessing cyclical variations of margins and prices.

To avoid the problems of using accounting data for estimating the price-cost margin, Domowitz (1992) takes an approach that examines total factor productivity. He adjusts the Solow residual to allow firms to price above marginal cost and then permits the price-cost margin to vary with the level of aggregate demand as measured by capacity utilization in manufacturing. Domowitz's point estimates indicate that there is a negative correlation between the margin and aggregate demand movements; however, the standard errors are large enough so that the null hypothesis of acyclicality cannot be rejected.

Bresnahan and Suslow (1989) study the aluminum industry and do not find any evidence of oligopoly market power. They develop an econometric model of short run supply, capacity constraints, and long-lived capital. Employing a switching regression model, they find evidence of two regimes in their reduced form quantity-produced and quantity-shipped equations. The implication is that in the high demand regime, prices are competitive (determined by the vertical portion of the supply curve) when production is constrained at capacity. Output is unconstrained in the second regime, output falls well short of capacity, and prices are determined by linear average variable costs. The aluminum industry is part of one of the industry groups considered in our empirical analysis. Our empirical results for this industry are largely consistent with theirs; we find no evidence of price markups above the competitive price in recessions for this industry. However, this industry is the exception rather than the rule among the industries that we examine.

Wilson (1998) reports evidence from laboratory experiments on oligopoly pricing. The experiments are similar to the posted offer pricing experiments of Davis and Holt (1994) except that Wilson considers the effects of a demand shift rather than the effects of a supply/capacity 
change. The results are broadly consistent with the model's predictions. When demand is high, prices are near the short run competitive level. When demand is low, prices remain above the short run competitive level and prices are more variable than when demand is high. When demand is low prices fail to conform precisely to the equilibrium mixed strategy predictions but appear to follow a disequilibrium process similar to an Edgeworth cycle process.

\section{Theoretical Model}

We develop a dynamic duopoly model of capacity investment and pricing. Each firm makes a sequence of investment and price decisions over an infinite horizon. Each time period is divided into two stages. In stage one firms simultaneously invest in production capacity. In stage two firms simultaneously choose prices, having observed capacity choices from stage one. The level of demand is uncertain when firms make investment decisions but is known before firms make pricing decisions. ${ }^{3}$

We utilize a simple "step demand" formulation. All consumers are assumed to have a common value, $v$, for one unit of the product. Let $a_{t}$ denote the market size (number of consumers) in period $t$. For any price less than or equal to $v$, the quantity demanded in period $t$ is $a_{t}$.

Market size evolves probabilistically. $s_{t}$ is the "state" at date $t$ and takes on the value of one or two. The evolution of the state variable is governed by a Markov chain process with, $\phi_{i j}=\operatorname{Prob}\left[s_{t}=j \mid s_{t-1}=i\right], i, j \in\{1,2\}$. The size of the market follows a state dependent trend $a_{t+1}=\tau_{s_{t+1}} a_{t}$ where $\tau_{1}>\tau_{2}>0$. In percentage terms, demand growth between $t$ and $t+1$ is, $\ln \left(a_{t+1}\right)-\ln \left(a_{t}\right)=\ln \left(\tau_{s_{t+1}}\right)$. This Markov model of demand growth is utilized in Bagwell and Staiger's (1997) theoretical analysis of collusive pricing over the business cycle (they assume a downward sloping demand, rather than a step demand). The same type of Markov model is also used in Hamilton's (1989) econometric analysis of aggregate U.S. business cycle fluctuations. His formulation involves an unobserved (for the econometrician) state variable that indicates whether the economy is in a low-growth or a high-growth state. Hamilton develops an estimation procedure for this model and finds that it provides a good characterization of aggregate business cycle fluctuations. ${ }^{4}$ We adopt a similar approach in our empirical analysis, where we permit values of the state variable over time to be determined endogenously by the data.

Capacities are chosen in the first stage of each period. In stage one of period $t, a_{t-1}$ and 
$s_{t-1}$ are known, but $a_{t}$ is unknown. If $s_{t-1}=i$, then $\phi_{i 2}$ is the probability of low growth (or contraction if $\tau_{2}<1$ ) from $t$-1 to $t$. Firms choose prices in stage two of period $t$ after observing the level of demand, $a_{t}$. Another interpretation is that firms are producing to a stock each period, but it is after production occurs that the firms learn the actual level of demand (market size) and choose prices. For industries with large irreversible capacity investments (e.g., chemicals), this must be the interpretation.

The marginal cost of capacity in the first stage is $c$. Firm one chooses capacity $x_{t}$ and firm two, capacity $y_{t}$, in period $t$. The marginal cost of production is constant in stage 2 , and is normalized to zero. The parameter $v$ can be interpreted as the value of the good minus the short run marginal production cost. We assume that both firms know $v$ and $c$, with $v>c>0$.

We first seek a characterization of noncooperative Nash equilibrium investment and pricing strategies for the two-stage game within a single time period. Later in this section we explain how single period equilibria may be linked together to form an equilibrium for the infinite horizon game. The level of demand is observed before firms set prices in stage two. A subgame in stage two of period $t$ is defined by the triple, $\left(x_{t}, y_{t}, a_{t}\right)$. There are three cases to consider. First, suppose that $x_{t}+y_{t} \leq a_{t}$. This is region $A$ in the graph of capacity pairs in Figure 1. If capacities are in region $A$, then a price equal to $v$ is a dominant strategy for each firm. Note that $v$ is also the short run competitive price when capacities are in $A .^{5} \mathrm{~A}$ firm's subgame payoff (revenue) is simply $v$ times its capacity. Second, suppose that $x_{t} \geq a_{t}$ and $y_{t} \geq a_{t}$. Each firm has enough capacity to serve the market by itself and the pricing subgame corresponds to a situation of Bertrand price competition. This is region $B$ in Figure 1. The unique subgame Nash equilibrium (NE) has each firm setting price equal to zero (the short run competitive price) and earning zero in the subgame. The final case is represented by region $C$ in Figure 1. Total capacity exceeds the size of the market, but at least one firm is too small to serve all consumers by itself. In this case there is no pure strategy equilibrium for the pricing subgame (except for the trivial case in which one firm's capacity is zero). A subgame Nash equilibrium involves mixed strategies for prices. Subgame equilibrium price distributions and expected revenues for region $C$ may be derived using an approach similar to Kreps and Scheinkman (1983). The expected revenue for firm one in the stage two subgame equilibrium of period $t$ is given by the following function: 


$$
r\left(x_{t}, y_{t}, a_{t}\right)= \begin{cases}v x_{t} & \left(x_{t}, y_{t}\right) \in A \\ v\left(a_{t}-x_{t}\right) x_{t} / y_{t} & \left(x_{t}, y_{t}\right) \in C, x_{t} \leq y_{t}<a_{t} \\ v\left(a_{t}-x_{t}\right) x_{t} / a_{t} & \left(x_{t}, y_{t}\right) \in C, x_{t}<a_{t} \leq y_{t} \\ v\left(a_{t}-y_{t}\right) & \left(x_{t}, y_{t}\right) \in C, x_{t}>y_{t} \\ 0 & \left(x_{t}, y_{t}\right) \in B\end{cases}
$$

Expected revenue for firm two is given by, $r\left(y_{t}, x_{t}, a_{t}\right)$.

In stage one firms choose capacities. The level of demand is uncertain in stage one. Expected profit in period $t$ as a function of capacities is

$$
\pi\left(x_{t}, y_{t}, a_{t-1}, s_{t-1}\right)=\phi_{s_{t-1}, 1} r\left(x_{t}, y_{t}, \tau_{1} a_{t-1}\right)+\phi_{s_{t-1}, 2} r\left(x_{t}, y_{t}, \tau_{2} a_{t-1}\right)-c x_{t}
$$

for firm one and $\pi\left(y_{t}, x_{t}, a_{t-1}, s_{t-1}\right)$ for firm two.

The following two assumptions are utilized.

Assumption 1: $\left(1-\phi_{i 2}\right) v>c, i=1,2$

Assumption 2: $\frac{3}{2} \tau_{2}>\tau_{1}$

Assumption 1 is a condition that makes it attractive for firms to invest so that total capacity is sufficient to serve all consumers when demand is high. Without $A 1$, firms would not (collectively) invest in capacity beyond the lowest possible of demand $\left(\tau_{2} a_{t-1}\right)$, and excess capacity would never emerge. Assumption 2 limits the difference in demand levels; high demand is no more than 50 percent above low demand. In the absence of a condition like this, an equilibrium may involve a Bertrand-type outcome with prices equal to short run marginal cost when demand is low.

Under Assumptions 1 and 2 a pure strategy equilibrium in capacity choices exists in each period $t$, conditional on the pair, $\left(a_{t-1}, s_{t-1}\right)$. The derivations appear in the Appendix. There are two types of reaction function configurations. If $\phi_{s_{t-1}, 2} \leq \tau_{1}(v-c) /\left(3 v \tau_{1}-2 v \tau_{2}\right)$, then reaction functions are as in Figure 2A. There is a continuum of equilibria, which includes a symmetric capacity pair. If $\phi_{s_{t-1}, 2}>\tau_{1}(v-c) /\left(3 v \tau_{1}-2 v \tau_{2}\right)$, then reaction functions are as in Figure $2 \mathrm{~B}$. Again, there is a continuum of equilibria. However, the equilibrium set does not include a symmetric capacity pair because reaction functions have a discontinuity involving a "jump" across the 45 degree line.

The main results for the two-stage game within a single time period may be summarized as follows. ${ }^{6}$ There is a continuum of equilibria. Equilibrium capacities in period $t$ sum to the 
level of high demand, $\tau_{1} a_{t-1}$. If demand is high, then in stage two both firms set price $v$, which is the upper bound of the set of short run market clearing prices. There is no excess capacity. If demand is low, then in stage two both firms adopt mixed strategies for prices, with prices above the short run market-clearing price of zero. Prices have positive variance and excess capacity emerges. An illustration of equilibrium price distributions for a low demand realization is provided in Figure 3. The figure illustrates the skewness of pricing distributions that is a feature of equilibrium mixed strategies in Bertrand-Edgeworth models.

We use the term price markup to indicate the difference between a firm's price and the (maximum) short run competitive price. Equilibrium prices are procyclical while equilibrium price markups are countercyclical in the simple two-stage game. The term "markup" is often used to indicate the difference between the price and short run marginal cost. In our setting, when demand is low, the conventional definition of a markup coincides with ours. However, short run marginal cost is not defined for output equal to capacity when demand is high, and hence we use the short run competitive price as the benchmark in that state.

Now consider the infinite horizon game beginning in period one, given initial conditions, $\left(a_{0}, s_{0}\right)$. Let $\delta$ be a common discount factor, where we assume that $\tau_{1} \delta<1$ so that payoffs are bounded. We focus on equilibria that have two features: ${ }^{7}$ (1) firms use strategies that constitute an equilibrium for the two-stage game in each period $t$, conditional on $\left(a_{t-1}, s_{t-1}\right)$, and (2) the market shares of capacities are the same whenever the previous period state is the same. Equilibria with these features yield a stationary Markov process for price and quantity changes. Note that other, more complex, equilibria may exist. For example, Bagwell and Staiger (1997) consider collusive mechanisms that can be supported as noncooperative Nash equilibria in a dynamic pricing game (without capacity constraints) with essentially the same probabilistic demand growth model that we use.

Suppose that $\left(s_{t-1}, s_{t}\right)=(1,2)$; i.e., there is high growth in $t$-1 and low growth in $t$. Then in period $t$ firms utilize mixed strategy distributions of prices. As long as $s_{t-1}=1$, this distribution is the same, regardless of the value of $a_{t-1}$, given the features of the equilibrium we consider. Let $m_{1 t}$ be a random variable representing the average of the two firms' prices, based on their mixed strategies, with $m_{1 t} \in(0, v], E\left(m_{1 t}\right)=\bar{m}_{1}<v$, and $\operatorname{Var}\left(m_{1 t}\right)=\sigma_{m_{1}}^{2}$.

Suppose instead that $\left(s_{t-1}, s_{t}\right)=(2,2)$; i.e., there is low growth in periods $t-1$ and $t$. Firms utilize mixed strategy distributions of prices and, as long as $s_{t-1}=2$, this distribution is the 
same, regardless of the value of $a_{t-1}$. Let $m_{2 t}$ be a random variable representing the average of the two firms' prices, based on their mixed strategies, with $m_{2 t} \in(0, v], E\left(m_{2 t}\right)=\bar{m}_{2}<v$, and $\operatorname{Var}\left(m_{2 t}\right)=\sigma_{m_{2}}^{2}$.

Up to this point our analysis has dealt with levels of prices. However, as we document in the last part of Section IV, industry time series of price levels are non-stationary. Therefore we utilize data on price changes rather than price levels in our empirical analysis. With two states the model makes four predictions for price and quantity changes. Let $p_{t}$ and $q_{t}$ represent the percentage change in prices and quantity, respectively. The results are derived in the last section of the Appendix and summarized in Table I. The testable implications of the model are twofold. First, during recessions $\left(s_{t}=2\right)$ the model predicts that changes in price will have a larger variance than during booms. ${ }^{8}$ Second, the form of the distribution of price changes will be different in recessions than in booms. In our theoretical model, there is price variation arising from mixed strategy pricing during recessions and no price variation in boom periods. In a more general formulation, price variation due to mixing during recessions would be in addition to other possible sources of price variation that might occur in both booms and recessions. For example, prices in booms may be normally distributed, while prices in recessions consist of a normally distributed component plus a non-normally distributed component due to mixed strategy pricing. This would generate price changes in recessions that have a distribution that is not Gaussian.

\section{Estimation Approach, Data and Empirical Analysis}

The business cycle formulation of the previous section generates a specific time series model of price and quantity changes. However, some features of the model are too restrictive. For example, due to our "step demand" formulation, the predicted variance of quantity changes is zero in each state; only two different quantity-change amounts are predicted to appear. A more general model with downward sloping demand would generate non-zero quantity change variances. ${ }^{9}$ In what follows we specify an empirical model that is more general than what is laid out in Table I. This specification permits a nonzero covariance between price and quantity changes and a positive variance for quantity change is permitted in each state. Since the state variable is not observable, the observed path of price and quantity changes must be used to make inferences about the values of the state variable (as with the Kalman filter). The unobserved 
state is assumed to be one of two growth rates, "high" or "low," and the probabilistic switch from one state to another is assumed to follow a Markov process. This approach to the issue of cyclical pricing is appealing because the data will determine when an industry switches regimes and whether relative price changes are more variable or not in recessions.

\section{Time Series Model}

The model we use is of the type formulated by Engel and Hamilton (1990) to test the hypothesis of uncovered interest parity. Let $\mathbf{y}_{t}=\left[q_{t}, p_{t}\right]^{\prime}$ be a two-dimensional vector at date $t$ where $q_{t}$ is the percentage change in production and $p_{t}$ is the percentage change in price for a particular industry. There is an unobservable variable, $s_{t}$, which characterizes the "state" at date $t$ and takes on the value of one or two. In Engel and Hamilton (1990), $\mathbf{y}_{t}$ is drawn from one bivariate distribution if the state in $t$ is equal to one and a second bivariate distribution if the state in $t$ is equal to two. Our setting is somewhat more complex, in that we have predictions on the distribution governing $\mathbf{y}_{t}$ draws conditional on both the current and the prior state (recall Table I). Depending on the current and prior states, the contemporaneous changes in the growth rates of production and real prices are drawn from a $N\left(\mu_{s_{t-1}, s_{t}}, \Omega_{s_{t-1}, s_{t}}\right)$ distribution. Thus, there are four different bivariate distributions governing $\mathbf{y}_{t}$ draws, since the pair $\left(s_{t-1}, s_{t}\right)$ can take on four different values.

The state variable follows the Markov chain process specified in Section I. Only through $s_{t-1}$ do past realizations of $\mathbf{y}$ and $s$ affect the unobservable state variable. Note that the draws of $\mathbf{y}_{t}$ are not independent draws from a mixture of normal distributions. The inferred probability that $\mathbf{y}_{t}$ is drawn from one distribution depends on all the realizations of $\mathbf{y}$ prior to time $t$. This approach differs from the Bresnahan and Suslow (1989) switching regime regression in that all prior information is used to infer the current probability that $\mathbf{y}_{t}$ is drawn from a particular distribution.

The bivariate model of stochastic segmented trends permits a wide variety of behavior for the series. First, the industry mean production growth rates may pick up slow or fast growth rates of production for an industry. The production growth rates could also be the same in both regimes, or one state may reflect recessionary periods and the other expansionary periods. Likewise, these combinations are possible for the contemporaneous real price regimes.

The model described above is the basis for estimation of a parameter vector, 
$\theta=\left(\mu_{11}, \mu_{12}, \mu_{21}, \mu_{22}, \Omega_{11}, \Omega_{12}, \Omega_{21}, \Omega_{22}, \phi_{11}, \phi_{22}\right)^{\prime}$. This vector has 22 parameters. The sample $\log$ likelihood function, $\ln p\left(\mathbf{y}_{T}, \mathbf{y}_{T-1}, \ldots, \mathbf{y}_{1} ; \theta\right)$, which is to be maximized with respect to the unknown parameters of $\theta$, can be constructed from the conditional likelihood of $\mathbf{y}_{t}$. The conditional likelihood of $\mathbf{y}_{t}, p\left(\mathbf{y}_{t} \mid \mathbf{y}_{t-1}, \ldots, \mathbf{y}_{1} ; \theta\right)$, is a byproduct of Hamilton's (1989) filtering algorithm. We can infer the probability that $\mathbf{y}_{t}$ was drawn from a particular state $s_{t}$ based on all information available at time $t: p\left(s_{t} \mid \mathbf{y}_{1}, \ldots, \mathbf{y}_{t} ; \theta\right)$. Furthermore, a full sample smoother can be used to draw inference on the regime at date $t$ using all the information available ex post: $p\left(s_{t} \mid \mathbf{y}_{1}, \ldots, \mathbf{y}_{T} ; \theta\right) .^{10,11}$

\section{The Data}

The price and output measures considered for this study are monthly time series. The Federal Reserve publishes indices of industrial production associated with the Bureau of Labor Statistics' Producer Price Index commodity series at the monthly level. ${ }^{12}$ For this study we limit ourselves to considering industries first at the two-digit Standard Industrial Classification level and then at the three-digit level if there are industry definition problems at the two-digit level.

The PPI's at various levels of aggregation are the natural choice for the price series. ${ }^{13}$ To form a relative industry price, the aggregate PPI is used to deflate an individual industry price index. If the corresponding PPI for an industry at the two-digit SIC level is too broad, we then look at industries at the three-digit level where we can get a closer match of the production and producer price series. The industries and associated price indices included in this study are listed in Table II.

The first observation for $\mathbf{y}_{t}$ is either January, 1960, or the earliest date following January, 1960, when both price and production series data first become available; the final observation is December, 1995. The originally unseasonalized price and production series are also individually deseasonalized using the basic structural model in Harvey (1993, pp. 142-44). In terms of the notation in the model described above, $q_{t}$ is 100 times the difference in natural logs of the index of industrial production, and $p_{t}$ is 100 times the difference in natural logs of the corresponding price index.

\section{Estimates and Business Cycle Specification Testing}

The model was estimated for twelve industries at the two-digit SIC level and five industries at the three-digit level. ${ }^{14,15}$ The estimated persistence of both boom and recessionary 
states is high for all industries, so there are only a small number of months representing transitions from one state to another. Because of this, the standard errors associated with estimates of $\mu_{12}, \mu_{21}, \Omega_{12}$, and $\Omega_{21}$ are large. Therefore, in Table III we report parameter estimates for the persistent states and the estimated state transition probabilities for each of the seventeen industries.

It is clear from the estimates that the filter is capturing the dynamics of business cycles as opposed to structural changes in positive growth rates. For fourteen of the seventeen industries, the production mean growth rate is statistically different from zero in state 1 . The mean change in production for state 2 is also negative for these fourteen industries, but not always statistically different from zero. ${ }^{16}$

The production growth rates for the newspaper (SIC 271) and metalworking machinery (SIC 354) industries are not statistically different from zero in state 1 or 2. Leather (SIC 31) production is trending down for the entire sample, and the mean growth rate in production in the food (SIC 20) industry is constant.

An alternative empirical approach is to estimate a model in which price and quantity changes depend on the current state $\left(s_{t} \in\{1,2\}\right)$ but not on the previous state. Such a model has two bivariate distributions for $p$ and $q$, rather than four. Ex post we find that there are very few month with transition states and so for ease of exposition and computation the statistical tests below that compare means and variances in different states are based on estimates from this two state model. The point estimates and the standard errors from estimating such a two-state model differ only slightly from those presented in Table III.

A Wald statistic for testing whether the means for one of the component series, $\mu_{s_{t}}$, are different across states is given by

$$
\frac{\left(\hat{\mu}_{1}-\hat{\mu}_{2}\right)^{2}}{\operatorname{vâr}\left(\hat{\mu}_{1}\right)+\operatorname{vâr}\left(\hat{\mu}_{2}\right)-2 \operatorname{côv}\left(\hat{\mu}_{1}, \hat{\mu}_{2}\right)},
$$

which is asymptotically distributed $\chi_{1}^{2}$. The asymptotic variance and covariance of the parameters, denoted by $\operatorname{var}\left(\hat{\mu}_{s_{t}}\right)$ and $\operatorname{cov}\left(\hat{\mu}_{1}, \hat{\mu}_{2}\right)$, are estimated from the inverse of the negative of the matrix of second derivatives. These statistics for the production and price series are reported in Table IV. Superscripts on the means denote the series: production $(q)$ and price $(p)$. The growth rates of production for the two states are significantly different for eight industries at the $\alpha=.05$ level of significance and ten industries at $\alpha=.10$. 
Figure 4 reports the estimated smoothed probability, $p\left(s_{t} \mid \mathbf{y}_{1}, \ldots, \mathbf{y}_{T} ; \hat{\boldsymbol{\theta}}\right)$, that the industry is in the recessionary regime (state 2) at date $t .{ }^{17} \mathrm{~A}$ reasonable criteria for inferring that the recessionary regime is more likely is $p\left(s_{t}=2 \mid \mathbf{y}_{1}, \ldots, \mathbf{y}_{T} ; \hat{\boldsymbol{\theta}}\right)>.5$. The smoothed inferences on state 2 indicate that the dates of the business cycle at the industry level are similar to the traditional NBER dates of business cycles. This first month of the recession in the mid 1970's is nearly uniform among these 17 industries, indicating that the filter is capturing the dynamics of the business cycle. For the chemical (SIC 28) industry, the filter dates the beginning of the 1973-75 recession as December, 1972, nearly a whole year earlier than the NBER date of 1973:IV. The turning point in April, 1975, however, is identical to the conventional NBER date, 1975:II. The chemical industry also experiences contractions conforming to the traditional recessions of 1980, 1981-82, and 1990-91. These, too, are present in the other industries but with more variation in the starting and ending dates. At the monthly and industry level the algorithm also indicates the common feature across industries of contractions in the early months of 1986 and in the latter half of 1994, but these rarely last more than three months.

Note that the filter typically permits a clear classification of months into regimes. The smoothed probabilities are usually very close to $0 \%$ or to $100 \%$. There are only 6 inferences between $40 \%$ and $60 \%$ for the chemical industry. The lumber (SIC 24) industry is an exception with frequent regime switches and more months with less conclusive inferences on the state.

The estimated switching probabilities can be used to calculate the expected duration of a regime. A regime $i$ is expected to last $\left(1-\phi_{i i}\right)^{-1}$ months. The postwar historical average recession according to NBER dating is 4.7 quarters which would imply that the probability of remaining in the production contraction regime is $92.01 \%$. Many of the industries have smaller probabilities suggesting shorter recessionary periods at the industry level.

Columns 3 and 4 in Table IV report the results of Wald tests of the null hypothesis that the growth rate of real prices is identical for both regimes. The chemical (SIC 28) industry is the only industry with countercyclical pricing trends, and the nonferrous metals industry (SIC 33:3$6,9)$ is the only industry with strong procyclical trends in real prices.

\section{Estimates of the Price Variance}

The primary testable implication of our non-collusive oligopoly model is that the variance of the price changes, $\sigma_{s_{t}, p}^{2}$, is greater in the recessionary regime than during times of 
production growth. Using a likelihood ratio test, the null hypothesis that we now test is

$$
H_{0}: \sigma_{1 p}^{2}=\sigma_{2 p}^{2} .
$$

The results from these tests are reported in Table V.

For every industry, save one, we can reject the null hypotheses of equal price change variance draws across regimes. As the estimates in Table III show, the recessionary variance for price changes is anywhere from 6 to 17 times the expansionary variance. For these sixteen industries, the average ratio of the state 2 price variance to the state 1 price variance is 11.69 . Because the inferred probabilities of being in either state are usually close to $0 \%$ or to $100 \%$, we are confident that the prices are much more variable in a recession than in an expansion.

The lone exception is the nonferrous metals industry (SIC 33:3-6, 9) for which the point estimates of the price variance are nearly identical. This classification includes the aluminum industry. Notice from Tables III and IV that the nonferrous metals industry is the only industry that has different mean price growth rates across regimes and which has negative price changes in recessions and positive price changes in expansions. Using $p\left(s_{t}=2 \mid \mathbf{y}_{1}, \ldots, \mathbf{y}_{T} ; \hat{\boldsymbol{\theta}}\right)>.5$ as the criteria for dating a recession, the levels of the real price by state are shown in Figure 5 for the nonferrous metals industry. Prices almost uniformly rise during expansions and fall during recessions, and as mentioned earlier, these price changes have equal variances. The sharp rise in the level of real prices as the industry reaches the peak of the business cycle is consistent with the Bresnahan and Suslow (1989) model in which firms are producing at the vertical portion of the short run supply curve during expansions. During contractions, however, the industry produces at short run marginal cost with considerable excess capacity such that equilibrium is in pure strategies. Bresnahan and Suslow document how competition increased in the aluminum market by observing that the Herfindahl index and concentration ratios fell for the U.S. aluminum industry from 1957-1982. It appears that there was too much competition and excess capacity in the Aluminum Industry for firms to set a price above the short run competitive price when demand was low. ${ }^{18}$

In addition to our theory, another source of increased price variation during contractions may be more variable input prices. However, the estimates from the machinery industry (SIC 35) seem to indicate that input costs are not likely responsible for the increase in the price change variance. All three-digit machinery industries plausibly have related mixes of the same inputs. If input cost variation is responsible for the price variation in both recessions and expansions, then 
a testable prediction is that the price change variance is the same in recessions and expansions for the three-digit machinery industries. As Table III indicates, the point estimates for the expansionary price change variance are identical (.168) for the agricultural machinery (SIC 352) and metalworking machinery (SIC 354) industries, but they differ in recessions, 1.620 and 2.341, respectively. This suggests that these two industries with similar inputs have different oligopoly pricing in recessions.

The food (SIC 20) industry may also provide some insight into how much of the increase in the price variance may be due to economy-wide reasons other than oligopoly pricing incentives. Our theory of oligopoly pricing may not be applicable to this industry because production in the food industry is growing at a constant rate throughout the sample (see Table III). Nevertheless, the filter estimates two empirically distinct regimes. Figure 4a illustrates that food industry is in regime 2 from 1973-1981 and from 1990-91. The former time period was a period of high inflation and general economic stagnation and the latter was the 1990-91 recession. As Table $\mathrm{V}$ reports, the two regimes for the food industry have statistically different price change variances, apparently for reasons not due to oligopoly pricing incentives. If this is a macroeconomic phenomenon, it may be a component of the state 2 price variances for the other industries which do experience expansions and contractions. However, the food industry's price change variance only increases by a factor of six, the smallest of all the significantly different variances (see Table V). For the fourteen industries that have distinct expansionary and recessionary states, the average ratio of the state 2 price change variance to the state 1 price change variance is 12.20 . This suggests that if there is a macroeconomic source for a higher price change variance in recessions, it is not responsible for all of the increased variance. Moreover, as the next subsection discusses, for the fourteen industries with expansions and contractions we find support for the additional prediction on the change in the form of the price change distribution.

\section{Capacity Utilization and Price Variance Ratios}

Capacity constraints play a crucial role in developing the theoretical predictions in Section III--the tighter the capacity constraints, the lower the variance of prices. With considerable excess capacity, the variance is also low. However, in the intermediate range of capacity constraints, the variance is higher. This suggests a quadratic relationship between capacity utilization and the ratio of the variances in Table V. Figure 6 plots average capacity utilization during recessions, as dated by the switching regime filter, against the ratio of price 
variances in Table $\mathrm{V}$ for thirteen of the fifteen industries that experience business cycles. ${ }^{19}$ Figure 6 also plots the fitted values from an OLS regression of the price variance ratio on capacity utilization, capacity utilization squared, and a constant. This regression is consistent with the prediction that the variance of recessionary prices is greatest for intermediate levels of capacity utilization, but the quadratic relationship is sensitive to single observations.

\section{Distribution of Price Draws}

We have assumed that $\mathbf{y}_{t}$ has bivariate normal distributions in all states. Assuming that expansionary price changes come from a normal distribution, the model predicts that recessionary price changes come from a non-normal distribution because firms use non-normal mixed strategy distributions for prices during recessions. ${ }^{20}$ Following the work of Newey (1985) and Hamilton (1996), we make use of the score statistics in tests that certain moment restrictions of the normal distribution hold for the data for both regimes. In particular, we will take the standard approach and examine the third and fourth moments, jointly and individually for each series. The null hypothesis then implies the following expectations hold for the joint test:

$$
\begin{aligned}
& E\left\{\sum_{s_{t}=1}^{2} p\left(s_{t}=S_{t} \mid \mathbf{y}_{1}, \ldots, \mathbf{y}_{T} ; \theta\right)\left(\mathbf{y}_{t}-\boldsymbol{\mu}_{s_{t}}\right)^{3}\right\}=0 \text { and } \\
& E\left\{\sum_{s_{t}=1}^{2} p\left(s_{t}=S_{t} \mid \mathbf{y}_{1}, \ldots, \mathbf{y}_{T} ; \theta\right) \cdot\left[\left(\mathbf{y}_{t}-\mu_{s_{t}}\right)^{4}-3\left[\begin{array}{c}
\sigma_{s_{t}, q}^{4} \\
\sigma_{s_{t}, p}^{4}
\end{array}\right]\right]\right\}=0
\end{aligned}
$$

Hamilton (1996) provides the scores for the univariate case, which can be naturally extended to the bivariate model. The sample counterparts to the above moment restrictions are

$$
\mathbf{r}=\frac{1}{T} \sum_{t=1}^{T}\left[\begin{array}{l}
\sum_{s_{t}=1}^{2} p\left(s_{t}=S_{t} \mid \mathbf{y}_{1}, \ldots, \mathbf{y}_{T} ; \hat{\boldsymbol{\theta}}\right)\left(\mathbf{y}_{t}-\hat{\boldsymbol{\mu}}_{s_{t}}\right)^{3} \\
\left.\sum_{s_{t}=1}^{2} p\left(s_{t}=S_{t} \mid \mathbf{y}_{1}, \ldots, \mathbf{y}_{T} ; \hat{\boldsymbol{\theta}}\right) \cdot\left[\left(\mathbf{y}_{t}-\hat{\boldsymbol{\mu}}_{s_{t}}\right)^{4}-3\left[\begin{array}{c}
\hat{\sigma}_{s_{t}, q}^{4} \\
\hat{\sigma}_{s_{t}, p}^{4}
\end{array}\right]\right]\right] .
\end{array}\right] .
$$

Let $\mathbf{M}$ be the $T \times 4$ matrix whose $t^{\text {th }}$ row is given by

$$
\left(\sum_{s_{t}=1}^{2} p\left(s_{t}=S_{t} \mid \mathbf{y}_{1}, \ldots, \mathbf{y}_{T} ; \theta\right)\left(\mathbf{y}_{t}-\mu_{s_{t}}\right)^{3}\right)^{\prime},\left(\sum_{s_{t}=1}^{2} p\left(s_{t}=S_{t} \mid \mathbf{y}_{1}, \ldots, \mathbf{y}_{T} ; \theta\right) \cdot\left[\left(\mathbf{y}_{t}-\mu_{s_{t}}\right)^{4}-3\left[\begin{array}{c}
\sigma_{s_{t}, q}^{4} \\
\sigma_{s_{t}, p}^{4}
\end{array}\right]\right)\right)^{\prime},
$$

and let the matrix $\mathbf{D}$ be the $T \times 12$ matrix of scores. For $\mathbf{S}=\frac{1}{T}\left(\mathbf{M}^{\prime} \mathbf{M}-\mathbf{M}^{\prime} \mathbf{D}\left(\mathbf{D}^{\prime} \mathbf{D}\right)^{-1} \mathbf{D}^{\prime} \mathbf{M}\right)$, the 
Wald statistic, $T \mathbf{r}^{\prime} \mathbf{S}^{-1} \mathbf{r}$, is asymptotically distributed as a $\chi_{4}^{2}$ and tests whether $q_{t}$ and $p_{t}$ are jointly normally distributed. For only testing one restriction (column) of $\mathbf{M}$, the test statistic is asymptotically $\chi_{1}^{2}$.

The results of the joint and individual tests for skewness and kurtosis are reported in Table VI. Column 2 reports the statistic for the joint test of normality for both regimes. There are clear rejections for all industries except food (SIC 20). Most of the individual series reject the null hypotheses of no skewness and/or kurtosis equal to 3. Recall that the moments being tested include both states.

Histograms of the price draws by state are shown in Figure 7. A price change is considered to be in state $j(j=1,2)$ if $p\left(s_{t}=j \mid \mathbf{y}_{1}, \ldots, \mathbf{y}_{T} ; \hat{\theta}\right)>.5$. These histograms for the price draws in state 1, the expansionary state, appear to be consistent with a normal distribution whereas the state 2 draws clearly are not. The variances of these draws are larger as our tests above indicate, and the skewness and non-normal kurtosis detected in the conditional moment tests is apparently coming from the recessionary price draws. Many of the industries have state 2 price draws with means shifted to the left, but with longer tails to the right. ${ }^{21}$ Other industries like electrical machinery (SIC 36) and metalworking machinery (SIC 353) appear to have bimodal price distributions during recessions.

\section{Price Levels over the Business Cycle}

Our simple theoretical model yields a prediction regarding price levels as well as predictions about price changes. Specifically, the model predicts that price levels are procyclical. Our empirical analysis has focused on the pattern of (percentage) price changes, rather than price levels, over the business cycle. The main reason for this focus is the non-stationarity our of real price level data. One cannot reject the hypothesis of a unit root for the (log of) real price data, using Dickey-Fuller critical values, for each of the 17 industry price series. A direct comparison of average price levels in expansions with average price levels in contractions can be misleading when the price series is non-stationary.

In what follows we examine the prediction that price levels are procyclical, taking into account the non-stationarity of prices. Rather than using a binary classification of expansions and recessions (either our endogenous classification, or the NBER dating), we use monthly data on capacity utilization in the manufacturing sector as a measure of the "state of demand" for 
manufacturing as a whole. ${ }^{22}$ Let $z_{t}$ be capacity utilization in manufacturing in month $t$. Consider the following two alternative relationships between the (log of) real price in industry $j$ in month $t$ and capacity utilization, $z_{t}$ :

$$
\begin{aligned}
& \ln P_{j t}=\alpha_{j}+\gamma_{j} t+\beta z_{t}+\varepsilon_{j t} \\
& \ln P_{j t}=\alpha_{j}+\gamma_{j} t+\beta z_{t}+\theta \ln P_{j, t-1}+\mu_{j t}
\end{aligned}
$$

In both relationships, the level of (log) real price is related to the "state of demand" via the coefficient $\beta$. A positive $\beta$ would indicate procyclical price levels, a negative $\beta$ would indicate counter-cyclical price levels, and a zero $\beta$ would indicate acyclical price levels. Differencing these two equations yields, respectively:

$$
\begin{aligned}
& \ln P_{j t}-\ln P_{j, t-1} \equiv p_{j t}=\gamma_{j}+\beta \Delta z_{t}+e_{j t} \\
& \ln P_{j t}-\ln P_{j, t-1} \equiv p_{j t}=\gamma_{j}+\beta \Delta z_{t}+\theta p_{j, t-1}+u_{j t}
\end{aligned}
$$

Equation (2) is very similar to (9.12), estimated in Domowitz (1992). Domowitz uses the same change in capacity utilization variable for manufacturing as a whole, though he uses yearly rather than monthly data. ${ }^{23}$

OLS estimates for these 2 specifications are reported in Table VII. Specification (2) is clearly better in terms of goodness of fit. Both models yield positive, significant coefficients for $\beta$, which is consistent with procyclical real price levels for our data sample. The estimated economic significance of changes in capacity utilization is fairly small. An increase in capacity utilization of 10 percent (a large increase) yields about a one-half percent real price increase, based on estimation of (1) and (2). Domowitz's estimates for $\beta$ tend to negative. They are significant for some subsamples (e.g., for what he calls the trigger-strategy sample of industries) but his estimate is not significant for the entire sample. So he cannot reject the hypothesis of acyclical price levels for the entire sample.

\section{Concluding Remarks}

Our theoretical analysis predicts that output price changes exhibit higher variance during recessions than during boom periods and that the form of the distribution of price changes differs across recession and boom periods. The analysis also predicts that the markup of output price over the short run competitive price (conditional on demand and capacity levels) is higher in recessions than in booms. Evidence from U.S. manufacturing industries is consistent with the hypothesis that price changes have higher variance in recessions than in booms. In fact, price 
changes are much more variable in recessions than in booms for almost all industries studied. In addition, the frequency distributions of these price changes in recessions are distinctly unlike their expansionary counterparts.

While we do not provide any direct evidence regarding price markups, the evidence presented here is consistent with the view that oligopoly firms charge prices involving a higher markup over the short run competitive price during recessions than during boom periods. This pattern of markups may amplify the effects of demand shocks on output. This in turn may provide a mechanism through which oligopoly market power exacerbates the effects of aggregate demand shocks on the macroeconomy.

The variation in price changes over the business cycle that we identify could be accounted for by an optimal collusion model such as Staiger and Wolak (1992) or by a noncollusive model similar to ours. ${ }^{24}$ Each of these models has the following features: there is demand uncertainty, firms have market power, firms have production capacity constraints, and firms set prices. We might add that if non-collusive models of market power are capable of explaining key empirical regularities, then analysts may not need to turn to relatively more complicated optimal collusion models of behavior over the business cycle.

Future research may focus on how industry concentration is related to the variance of price changes at a more disaggregated industry level and how nature of costs affects oligopoly pricing incentives. Forming larger systems by grouping industries together may also improve estimation efficiency and increase the number of significant parameters. Since the empirical results suggest that the form of the distribution of price changes differs across recessionary and boom regimes, it would also seem worthwhile to develop a more sophisticated econometric model of the recessionary regime. Extending our model to include product differentiation and semi-flexible capacity constraints, along the lines of the work by Maggi (1996), would likewise be a productive avenue of research. 


\section{Appendix}

\section{Analysis of Two-Stage Game}

In stage one, firm one's expected profit is,

$$
\pi\left(x_{t}, y_{t}, a_{t-1}, s_{t-1}\right)=\phi_{s_{t-1}, 1} r\left(x_{t}, y_{t}, \tau_{1} a_{t-1}\right)+\phi_{s_{t-1}, 2} r\left(x_{t}, y_{t}, \tau_{2} a_{t-1}\right)-c x_{t},
$$

where $r(\cdot)$ is the expected subgame revenue, defined in Section III. $\pi$ is continuous in $\left(x_{t}, y_{t}\right)$ since $r(\cdot)$ is continuous in these arguments. However, $\pi$ is not differentiable in $x$ for all capacity levels, so one cannot rely exclusively on first-order conditions to characterize best responses. In order to simplify the exposition we drop the time subscripts from capacity variables, and we define $\theta \equiv \phi_{s_{t-1}, 2}, \underline{a} \equiv \tau_{2} a_{t-1}$, and $\bar{a} \equiv \tau_{1} a_{t-1}$. Using this notation, firm one's expected profit as a function of capacities is,

$$
\tilde{\pi}(x, y)=(1-\theta) r(x, y, \bar{a})+\theta r(x, y, \underline{a})-c x .
$$

Consider the investment incentives for firm one, conditional on firm one being the larger firm $(x>y)$. In this case Assumption 1 implies that expected profit is strictly increasing in $x$ for $x+y<\bar{a} ; \quad \tilde{\pi}(x, y)=v(E(a)-y)-c x$ for $x+y>\bar{a}$, so that $\tilde{\pi}$ is strictly decreasing when total capacity exceeds the high demand level; and $\tilde{\pi}$ is continuous in $x$ at $x=\bar{a}-y$. Therefore, if $y<\frac{1}{2} \bar{a}$ then $\tilde{\pi}$ reaches a local maximum at $x=\bar{a}-y$. This may not be a global maximum since $\tilde{\pi}$ may attain a higher value for some $x<y$.

The payoffs for firm one are more complex when it is the smaller firm $(x<y)$. Consider first the best response to $y \in[\underline{a}, \bar{a}]$. Any best response will be less than $\underline{a}$, since Assumption 2 implies that $\tilde{\pi}$ is strictly decreasing in $x$ for $x \geq \underline{a}$. Given $y \in[\underline{a}, \bar{a}], \tilde{\pi}$ is strictly increasing in $x$ for $0 \leq x \leq \bar{a}-y$ by Assumption 2. $\tilde{\pi}$ is strictly concave in $x$ for $\bar{a}-y \leq x \leq \underline{a}$. In addition $\tilde{\pi}$ is continuous in $x$ at $x=\bar{a}-y$ with a left derivative that exceeds the right derivative So, there is a unique best response to each $y \in[\underline{a}, \bar{a}]$, which lies in $\bar{a}-y \leq x \leq \underline{a}$. This best response is,

$$
b(y)=\max \left\{\bar{a}-y, \frac{(\theta v-c) \underline{a} y+(1-\theta) v \bar{a} \underline{a}}{2(\theta v y+(1-\theta) v \underline{a})}\right\} .
$$

Suppose that $y \in\left[\frac{1}{2} \bar{a}, \underline{a}\right]$. If $x \leq \underline{a}-y$ then $\tilde{\pi}(x, y)=v x-c x$, which is strictly increasing in $x$. If $x \geq y$ then $\tilde{\pi}(x, y)=v(E(a)-y)-c x$, which is strictly decreasing in $x$. So any best response must be in $[\underline{a}-y, y]$. Firm one's expected profit function is not differentiable 
at $x=\bar{a}-y$; expected profit is strictly concave in $x$ for $x \in[\underline{a}-y, y]$. This implies that there is a unique best response to $y \in\left[\frac{1}{2} \bar{a}, \underline{a}\right]$ that lies in $[\underline{a}-y, y]$.

If the condition,

$$
\theta \leq \frac{\bar{a}(v-c)}{3 v \bar{a}-2 v \underline{a}},
$$

holds then the best response to $y \in\left[\frac{1}{2} \bar{a}, \underline{a}\right]$ is,

$$
b(y)=\max \left\{\bar{a}-y, \frac{1}{2}(E(a)-c y / v)\right\} .
$$

Condition (A2) is equivalent to the condition, $\phi_{s_{t-1}, 2} \leq \tau_{1}(v-c) /\left(3 v \tau_{1}-2 v \tau_{2}\right)$, in the main text. From (A3) it follows that $b\left(\frac{1}{2} \bar{a}\right)=\frac{1}{2} \bar{a}$ and $b(y)=\bar{a}-y$ for some interval of $y$-values extending above $y=\frac{1}{2} \bar{a}$. Inequality (A2) also implies that $\bar{a}-y$ is a best response to $y \in\left[0, \frac{1}{2} \bar{a}\right.$ ); i.e., the local best response for firm one as a large firm is also a global best response to $y \in\left[0, \frac{1}{2} \bar{a}\right)$. So, inequality (A2) yields a reaction function for firm one that is as depicted by $R_{1}$ in Figure $2 \mathrm{~A}$. The reaction function for firm two is defined symmetrically. The set of equilibria is the set of capacity pairs that sum to $\bar{a}$ such that neither $x$ nor $y$ exceed some critical value. This critical value is the lowest value of $y$ such that $b(y)$ in (A1) or (A3) exceeds $\bar{a}-y$.

If (A2) does not hold then a best response to $y \in\left[\frac{1}{2} \bar{a}, \underline{a}\right]$ may be less than $\bar{a}-y$. For some values of $y \in\left[\frac{1}{2} \bar{a}, \underline{a}\right]$, expected profit for firm one is maximized by choosing capacity,

$$
\tilde{x}(y) \equiv \frac{1}{2}[\underline{a}+(1-\theta-c / v) y / \theta] .
$$

This capacity choice is optimal for firm one when $\tilde{x}(y)<\bar{a}-y$, which is possible only when (A2) does not hold. If (A2) does not hold then $\tilde{x}\left(\frac{1}{2} \bar{a}\right)<\frac{1}{2} \bar{a}$ and $\tilde{x}(y)<\bar{a}-y$ for an interval of $y$-values exceeding $\frac{1}{2} \bar{a}$. The best response to $y \in\left[\frac{1}{2} \bar{a}, \underline{a}\right]$ is,

$$
b(y)=\min \left\{\tilde{x}(y), \max \left\{\bar{a}-y, \frac{1}{2}(E(a)-c y / v)\right\}\right\} .
$$

If (A2) does not hold there is also an interval of $y$-values below $\frac{1}{2} \bar{a}$ for which the best response is $\tilde{x}(y)<\bar{a}-y$. In such cases, there is a local maximum that involves firm one being the large firm and choosing capacity, $\bar{a}-y$; however, the global maximum is for firm one to respond as a small firm, choosing $\tilde{x}(y)<y$. Once $y$ becomes sufficiently small, firm one's best response 
"jumps" up to $\bar{a}-y$. The reaction correspondence for firm one is depicted as $R_{1}$ in Figure 2B. The set of equilibria is the set of capacity pairs that sum to $\bar{a}$ such that, (1) neither $x$ nor $y$ exceed a critical value defined in the previous paragraph and, (2) an interval of capacity pairs around $x=y$ is excluded (when firm two is the large firm, the excluded set involves $y$-values such that $\tilde{x}(y)<\bar{a}-y)$.

Illustration of the Derivations in Table 1

We define $p_{t} \equiv \ln P_{t}-\ln P_{t-1}$ and $q_{t} \equiv \ln Q_{t}-\ln Q_{t-1}$ where $P_{t}$ is the average price for sellers and $Q_{t}$ is total industry production in period $t$. The approximations of $p_{t}$ use a first order Taylor expansion:

$$
\ln (x) \approx \ln (E(x))+\frac{x-E(x)}{E(x)} .
$$

A derivation for the case, $s_{t-1}=1$ and $s_{t}=2$, is provided here. Derivations for the other three cases in Table I are similar to this. The period $t$ price is the random variable, $m_{1 t}$, where $m_{1 t} \in(0, v], E\left(m_{1 t}\right)=\bar{m}_{1}<v$, and $\operatorname{Var}\left(m_{1 t}\right)=\sigma_{m_{1}}^{2}$. The price in $t-1$ is, $v$. Thus we have,

$$
p_{t}=\ln \left(m_{1 t}\right)-\ln (v) \approx \ln \left(\frac{\bar{m}_{1}}{v}\right)+\frac{m_{1 t}-\bar{m}_{1}}{\bar{m}_{1}}
$$

and

$$
q_{t}=\ln a_{t}-\ln a_{t-1}=\ln \left(\tau_{2}\right) .
$$

The first and second moments are:

$$
\begin{gathered}
E\left(p_{t}\right)=\ln \left(\frac{\bar{m}_{1}}{v}\right)<0, \operatorname{Var}\left(p_{t}\right)=E\left[\left(p_{t}-\ln \left(\frac{\bar{m}_{1}}{v}\right)\right)^{2}\right]=E\left[\left(\frac{m_{1 t}-\bar{m}_{1}}{\bar{m}_{1}}\right)^{2}\right]=\frac{\sigma_{m_{1}}^{2}}{\bar{m}_{1}^{2}}, \\
E\left(q_{t}\right)=\ln \left(\tau_{2}\right), \text { and } \operatorname{Var}\left(q_{t}\right)=0 .
\end{gathered}
$$




\section{References}

Bagwell, K. and R. Staiger, "Collusion over the Business Cycle," Rand Journal of Economics, Spring 1997, 28, 82-106.

Bresnahan, T. F., "Empirical Studies of Industries with Market Power," in R. Schmalensee and R. Willig, eds., Handbook of Industrial Organization, 1989, 2, New York: North-Holland, 101157.

Bresnahan, T. F., and V. Y. Suslow, "Short run Supply with Capacity Constraints," Journal of Law and Economics, 1989, 32, S11-S41.

Chevalier, J., and D. Scharfstein, "Capital-Market Imperfections and Countercyclical Markups: Theory and Evidence,” American Economic Review, September 1996, 86, 703-725.

Davis, D. and C. Holt, "Market Power and Mergers in Laboratory Markets with Posted Prices," Rand Journal of Economics, Autumn 1994, 25, 467-487.

Dempster, A., N. Laird, and D. Rubin, "Maximum Likelihood from Incomplete Data via the EM Algorithm, Journal of the Royal Statistical Society, 1977, B 39, 1-38.

Domowitz, I., "Oligopoly Pricing: Time-Varying Conduct and the Influence of Product Durability as an Element of Market Structure," in The New Industrial Economics, eds. G. Norman and M. La Manna, Brookfield, VT: Elgar Publishing, 1992, 214-235.

Domowitz, I., R. G. Hubbard, and B. Petersen, "Oligopoly Supergames: Some Empirical Evidence on Prices and Margins," in T. Bresnahan and R. Schmalensee, eds., The Empirical Renaissance in Industrial Organization: An Overview, Oxford: Blackwell, 1987, p. 9-28.

Engel, C., and J. D. Hamilton, "Long Swings in the Dollar: Are They in the Data and Do Markets Know It?” American Economic Review, 1990, 80, 689-713.

Gottfries, N. "Customer Markets, Credit Market Imperfections, and Real Price Rigidity," Economica, 1991, 58(3), 317-23.

Greenwald, B., J. Stiglitz, and A. Weiss, "Informational Imperfections in the Capital Market and Macroeconomic Fluctuations," American Economic Review (Papers and Proceedings, 1984, 74(2), 194-99.

Hamilton, J. D. "A New Approach to the Economic Analysis of Nonstationary Time Series and the Business Cycle," Econometrica, 1989, 57(2), 357-384.

Hamilton, J. D. "Analysis of Time Series Subject to Changes in Regime," Journal of Econometrics, 1990 45, 39-70.

Hamilton, J. D. "A Quasi-Bayesian Approach to Estimating Parameters for Mixtures of Normal Distributions," Journal of Business and Economic Statistics, 1991, 9, 27-39. 
Hamilton, J. D. "Specification Testing in Markov-Switching Time-Series Models, Journal of Econometrics, 1996, 70, 127-157.

Harvey, A. C. Time Series Models. Cambridge, MA: MIT Press, 1993.

Klemperer, P. "Competition When Consumers Have Switching Costs: An Overview with Applications to Industrial Organization, Macroeconomics, and International Trade," Review of Economic Studies, 1995, 62, 515-39.

Kreps, D. M., and J. A. Scheinkman, "Quantity Precommitment and Bertrand Competition Yield Cournot Outcomes," Bell Journal of Economics, 1983, 14, 326-337.

Maggi, G. "Strategic Trade Policies with Endogenous Mode of Competition," American Economic Review, 86(1), 237-258.

Newey, W. "Maximum Likelihood Specification Testing and Conditional Moment Tests," Econometrica, 1985, 53, 1047-70.

Reynolds, S. and B.J. Wilson, "Bertrand-Edgeworth Competition, Demand Uncertainty, and Asymmetric Outcomes," Journal of Economic Theory, 2000, 92, 122-141.

Rotemberg, J. J., and G. Saloner, "A Supergame-Theoretic Model of Price Wars during Booms," American Economic Review, 1986, 76, 390-407.

Rotemberg, J. J., and M. Woodford, "Oligopolistic Pricing and the Effects of Aggregate Demand on Economic Activity," Journal of Political Economy, 1992, 100(6), 1153-207.

Rotemberg, J. J., and M. Woodford, "Markups and the Business Cycle," Macroeconomics Annual, 1991, 6, 63-129.

Staiger, R.W., and F. Wolak, "Collusive pricing with Capacity Constraints in the Presence of Demand Uncertainty", Rand Journal of Economics, Summer 1992, 23, 203-220.

Stiglitz, J. "Price Rigidities and Market Structure," American Economic Review (Papers and Proceedings, 1984, 74(2), 350-55.

White, H. "Maximum Likelihood Estimation of Misspecified Models," Econometrica, 1982, 50, $1-25$.

Wilson, B. J., "What Collusion? Unilateral Market Power as a Catalyst for Countercyclical Pricing," Experimental Economics, 1998, 1(2), 133-145. 
1 Two other implications of this non-collusive oligopoly model are noteworthy. First, price adjustments are sluggish in the downward direction, relative to competitive prices. If demand changes from high to low then oligopoly firms reduce prices by an amount less than the change in the competitive price, since oligopoly firms charge a markup over the short run competitive price when demand is low. A second (and related) implication is that existing capacity is utilized efficiently when demand is high but may be utilized inefficiently when demand is low. Oligopoly price markups above the short run competitive price can lead to less output and employment than is efficient when demand is low.

2 The model in Bagwell and Staiger (1997) does not predict that the variance of price changes will be greater in recessions than in expansions. Their unique prediction is that a high transitory demand shock within a recessionary or expansionary regime is associated with a lower most-collusive price. This would generate a negative covariance between price changes and quantity changes within recessions and expansions.

3 Reynolds and Wilson (2000) analyze more general two-stage models, including formulations with a downward sloping demand. However, the simple formulation of the present paper yields the principal empirical implications that we search for in the data.

4 The business cycle dates from Hamilton's filter closely correspond to the traditional NBER dates. It is also worth noting that the unobservable state is only one of many influences on the growth rate so that output could be falling even though the economy is in the "high" growth rate state.

5 If total capacity is less than $a$ then $v$ is the unique competitive price. If total capacity equals $a$ then $v$ is the upper bound on the interval of competitive prices.

6 The two-stage model is formulated as a duopoly. However, the basic results on markups and price variability continue to hold for markets with more than two firms, as long as the market does not become too competitive. For example, suppose that there are $n \geq 2$ equal sized firms, with total capacity equal to the maximum possible demand. If $n+1<\tau_{1} /\left(\tau_{1}-\tau_{2}\right)$, then when demand is low, equilibrium prices are draws from a mixed strategy distribution; prices involve a positive markup over short run marginal cost and prices have positive variance.

7 A sequence of equilibria for single period games constitute an equilibrium for the infinite horizon game because the choices that a firm makes in period $t$ have no effect on the payoffs of either firm in period $t+1$. We are assuming that capacity choices are reversible from one period to the next, so that period $t$ capacity choices have no impact on period $t+1$ capacities or payoffs. The market size in period $t+1$ is related to market size in period $t$, but the probabilistic transition of market size from one period to the next is unaffected by firms' decisions.

${ }^{8}$ If firms are mixing across periods during recessionary periods, then an index of these prices will vary over time. If the equilibrium during a boom is in pure strategies, then there is no source of variation due to mixing.

9 We should emphasize that the main predictions of the model regarding differential variances of price changes over the business cycle are not sensitive to our "step demand" assumption. In Reynolds and Wilson (2000) we show that the same pattern of price variances emerges in a model with downward sloping demand.

${ }^{10}$ Two issues arise when attempting to find the maximum likelihood estimate $\hat{\theta}$. Both involve the process of finding the global maximum of the sample log likelihood function. From the filter we can determine the sample log 
likelihood function as the sum of the conditional log likelihoods:

$\ln p\left(\mathbf{y}_{T}, \mathbf{y}_{T-1}, \ldots, \mathbf{y}_{1}\right)=\sum_{t=1}^{T} \ln p\left(\mathbf{y}_{t} \mid \mathbf{y}_{t-1}, \ldots, \mathbf{y}_{1}\right) . \quad$ As in Hamilton (1989) the sample log likelihood can be maximized using numeric hill-climbing methods, but systems with a large number of parameters (e.g., twenty-two) often have many local maxima and require lengthy computing time. Hamilton (1990) shows how the switching regime filter can be estimated using the EM (expected maximum likelihood) algorithm developed by Dempster, Laird, and Rubin (1977). With the EM algorithm, analytic derivatives are easily calculated from smoothed inferences. Furthermore, systems with a larger number of parameters, as in the bivariate model employed here, do not require additional iterations or computing time because the analytic derivatives are calculated from the smoothed probabilities. In addition to choosing the method for maximizing the likelihood function, another problem arises when the mean of the first state is set exactly equal to the first observation and the variance of the first state is allowed to vanish. In such a case the likelihood function blows up to infinity. Hamilton (1991) offers Bayesian priors as a solution to this problem. These positive Bayesian priors imply that one is now maximizing a generalized objective function that is not subject to these singularities. The first order conditions from maximizing the log likelihood function with and without the Bayesian priors are given in Hamilton (1990) and Engel and Hamilton (1990). In practice we find that this potential singularity in the likelihood function is not a problem with our data.

${ }^{11}$ The smoothed probability, $p\left(s_{t-1}=i, s_{t}=j \mid \mathbf{y}_{1}, \ldots, \mathbf{y}_{T} ; \theta\right)$, is calculated as part of the filter for the two-state model employed by Engel and Hamilton. In a two-state model, the transition observations from state $i$ in period $t-1$ to state $j$ in period $t$ are incorporated into the estimate of $\mu_{s_{t}=j}$ and $\Omega_{s_{t}=j}$. In practice we estimate a two-state model and use $p\left(s_{t-1}=i, s_{t}=j \mid \mathbf{y}_{1}, \ldots, \mathbf{y}_{T} ; \theta\right)$ to estimate the parameters from a four-state version of the EM equations in Hamilton (1990) (p.54).

${ }^{12}$ The results are similar if capacity utilization rates are used instead of industrial production.

13 The PPI data were downloaded from the BLS World Wide Web site http://stats.bls.gov/. We use price and quantity data with a monthly frequency. The model that we analyzed in Section III assumed that firms were able to choose both prices and capacity in each period. If firms could in fact adjust their capacities on a monthly basis then they might choose to reduce their production capacities significantly during recessionary regimes. However, this kind of significant capacity reduction is not observed in most recessions. Our Assumption 1 insures that value and cost parameters are such that even though firms could reduce capacity in anticipation of continued weak demand, that they would prefer to maintain enough capacity to meet a higher demand level.

${ }^{14}$ We thank James Hamilton for kindly distributing his Gauss code with which we replicated his results. Additional code was added for the likelihood ratio tests and bivariate conditional moment tests.

15 The following industries are not included: Tobacco (SIC 21), Textiles (SIC 22), Apparel SIC (23), and Instruments (SIC 38). The real price of tobacco was fairly constant from January, 1960, to August, 1982, after which it began a nearly deterministic climb from 102 in September, 1983, to 234 in July, 1993. Then the real price fell $24 \%$ in August, 1993, and does not change much for the rest of the sample. Clearly a more complicated model explaining these events is necessary before the switching regime model is applied. The BLS does not publish a 
price index solely for textiles, but one for Textiles and Apparel. It did publish a separate series for Apparel, but it ends in 1977. There is also no price index that adequately captures the general industry, Instruments (SIC 38). The five industries at the three-digit level represent three industries for which good measures of the price could not be found at the two-digit level.

${ }^{16}$ Furthermore, following Engel and Hamilton (1990) we use a general null hypothesis to test whether a series follows a random walk against the alternative of the two-state regime model. The Markov switching probabilities are not identified in the model when $\mu_{1}=\mu_{2}$ and $\Omega_{1}=\Omega_{2}$, but asymptotically valid tests of the following null hypothesis do exist- $\mathrm{H}_{0}: \phi_{11}=1-\phi_{22}, \mu_{1} \neq \mu_{2}$, and $\Omega_{1} \neq \Omega_{2}$. As in Engel and Hamilton, we test the null hypothesis of a random walk with both a Wald and likelihood ratio statistic. The Wald statistic is given by $\frac{\left[\hat{\phi}_{11}-\left(1-\hat{\phi}_{22}\right)\right]^{2}}{\operatorname{vâr}\left(\hat{\phi}_{11}\right)+\operatorname{vâr}\left(\hat{\phi}_{22}\right)+2 \operatorname{côv}\left(\hat{\phi}_{11}, \hat{\phi}_{22}\right)} \approx \chi_{1}^{2}$. The likelihood ratio test compares the unconstrained log likelihood to the largest $\log$ likelihood when $\phi_{11}=1-\phi_{22}$ and is asymptotically distributed as $\chi_{1}^{2}$. These test statistics are not reported here. The Wald test statistics are all larger (in some cases much larger) than the likelihood ratio test statistics, but the even the latter soundly rejects the null hypothesis of a random walk in favor of the two regime model. (The smallest LR statistic is greater than 68.) In sum, the switching regime model is capturing the dynamics of the business cycle for these industries.

${ }^{17}$ The evolving probabilities are similar to the smoothed inferences. Using all the information in the sample reduces the "noise" in the some of probabilities within a recession. For example, six months into the 1973-75 recession, the probability of being in the recessionary state falls from $99 \%$ to $70 \%$, but using all the information in the sample revises that estimate back to $99 \%$.

18 cf ft. 5 .

${ }^{19}$ We could not find data on capacity utilization for nonferrous metals (SIC 33:3-6, 9) and newspapers (SIC 271) that is consistent with the data used for prices and production, though we already discuss the former explicitly in the previous subsection.

${ }^{20}$ Even though the recessionary price changes may not be Gaussian, the estimates in Table III are consistent quasimaximum likelihood estimates (see White (1982)).

${ }^{21}$ These conditional moments tests are influenced, but not overwhelmingly so, by a common outlier in August, 1973. Food prices jumped $9 \%$ that month causing the overall PPI to rise abruptly. For many industries, this real price draw around $-5 \%$ is the lone outlying negative real price change.

22 Utilization is measured in percentage units. This data is available from the Federal Reserve Board web site, http://www.federalreserve.gov/releases/g17/download.htm.

23 The main differences between (2) and (9.12) in Domowitz are that we have an industry-specific dummy rather than a fixed constant, and Domowitz includes a cost change variable on the RHS. He uses instrumental variables for this cost change variable. We do not have data to serve as proxies for unit cost, as in Domowitz. However, our deflation of nominal prices by the producer price index will account for at least some of the effects of cost shocks. 
Domowitz uses changes in nominal prices rather than changes in real prices, as the dependent variable.

${ }^{24}$ Our results also indicate that there are as many positive as negative covariances (see the off diagonal results for $\Omega_{11}$ and $\Omega_{22}$ in Table III). Hence, the evidence does not support the Bagwell and Staiger prediction regarding transitory demand shocks in an optimal collusion mechanism ( $\mathrm{cf} \mathrm{ft.} \mathrm{2).}$ 
Table I

Model Predictions

\begin{tabular}{|c|c|c|}
\hline & 1 & 2 \\
\hline 1 & $\begin{array}{l}E\left(p_{t}\right)=0 \\
E\left(q_{t}\right)=\ln \tau_{1} \\
\operatorname{Var}\left(p_{t}\right)=0 \\
\operatorname{Var}\left(q_{t}\right)=0\end{array}$ & $\begin{array}{l}E\left(p_{t}\right)=\ln \left(\frac{\bar{m}_{1}}{v}\right)<0 \\
E\left(q_{t}\right)=\ln \tau_{2} \\
\operatorname{Var}\left(p_{t}\right)=\sigma_{m_{1}}^{2} / \bar{m}_{1}^{2} \\
\operatorname{Var}\left(q_{t}\right)=0\end{array}$ \\
\hline 2 & $\begin{array}{l}E\left(p_{t}\right)=\ln \left(\frac{v}{\bar{m}_{2}}\right)>0 \\
E\left(q_{t}\right)=\ln \tau_{1} \\
\operatorname{Var}\left(p_{t}\right)=\sigma_{m_{2}}^{2} / \bar{m}_{2}^{2} \\
\operatorname{Var}\left(q_{t}\right)=0\end{array}$ & $\begin{array}{l}E\left(p_{t}\right)=0 \\
E\left(q_{t}\right)=\ln \tau_{2} \\
\operatorname{Var}\left(p_{t}\right)=2 \sigma_{m_{2}}^{2} / \bar{m}_{2}^{2} \\
\operatorname{Var}\left(q_{t}\right)=0\end{array}$ \\
\hline
\end{tabular}

Table II

Industries and Associated Price Indices

\begin{tabular}{lll}
\hline \hline Industry & SIC Code & Price Index (BLS series) \\
\hline Foods & 20 & PPI, Processed foods and feeds (wpu02) \\
Lumber and products & 24 & PPI, Lumber and wood products (wpu08) \\
Furniture and fixtures & 25 & PPI, Furniture and household durables (wpu12) \\
Paper and products & 26 & PPI, Pulp, paper, and allied products (wpu09) \\
Newspapers & 271 & CPI, Newspapers (cuur0000se5901) \\
Chemicals and products & 28 & PPI, Chemicals and allied products (wpu06) \\
Petroleum products & 29 & PPI, Petroleum products refined (wpu057) \\
Rubber and plastic products & 30 & PPI, Rubber and plastic products (wpu07) \\
Leather and products & 31 & PPI, Leather (wpu042) \\
Clay, glass, and stone products & 32 & PPI, Nonmetallic mineral products (wpu13) \\
Nonferrous metals & $33: 3-6,9$ & PPI, Nonferrous metals (wpu102) \\
Fabricated metal products & 34 & PPI, Fabricated structural metal products (wpu107) \\
Agricultural machinery and equipment & 352 & PPI, Agricultural machinery and equipment (wpu111) \\
Construction machinery and equipment & 353 & PPI, Construction machinery and equipment (wpu112) \\
Metalworking machinery and equipment & 354 & PPI, Metalworking machinery and equipment (wpu113) \\
Electrical machinery and equipment & 36 & PPI, Electrical machinery and equipment (wpu117) \\
Transportation equipment & 37 & PPI, Transportation equipment (wpu14) \\
\hline
\end{tabular}


Table III

Maximum Likelihood Estimates for $\mathbf{y}_{t}=\left[q_{t}, p_{t}\right]^{\prime}$

\begin{tabular}{|c|c|c|c|c|c|c|c|c|c|c|c|c|}
\hline \multirow{2}{*}{$\begin{array}{l}\text { Parameter } \\
\mu_{11}^{q}\end{array}$} & \multicolumn{2}{|c|}{$\begin{array}{c}\text { Food } \\
\text { (SIC 20) }\end{array}$} & \multicolumn{2}{|c|}{$\begin{array}{c}\text { Lumber } \\
\text { (SIC 24) }\end{array}$} & \multicolumn{2}{|c|}{$\begin{array}{c}\text { Furniture } \\
\text { (SIC 25) }\end{array}$} & \multicolumn{2}{|c|}{$\begin{array}{c}\text { Paper } \\
\text { (SIC 26) }\end{array}$} & \multicolumn{2}{|c|}{$\begin{array}{l}\text { Newspaper } \\
\text { (SIC 271) }\end{array}$} & \multicolumn{2}{|c|}{$\begin{array}{c}\text { Chemicals } \\
\text { (SIC28) }\end{array}$} \\
\hline & $\begin{array}{c}0.219 \\
(0.048) *\end{array}$ & & $\begin{array}{r}0.260 \\
(0.118)\end{array}$ & & $\begin{array}{r}0.370 \\
(0.090)\end{array}$ & & $\begin{array}{r}0.326 \\
(0.076)\end{array}$ & & $\begin{array}{r}0.042 \\
(0.065)\end{array}$ & & $\begin{array}{r}0.494 \\
(0.043)\end{array}$ & \\
\hline$\mu_{11}^{p}$ & $\begin{array}{r}0.041 \\
(0.030)\end{array}$ & & $\begin{array}{r}0.057 \\
(0.060)\end{array}$ & & $\begin{array}{l}-0.065 \\
(0.020)\end{array}$ & & $\begin{array}{r}0.031 \\
(0.023)\end{array}$ & & $\begin{array}{r}0.124 \\
(0.034)\end{array}$ & & $\begin{array}{r}-0.075 \\
(0.023)\end{array}$ & \\
\hline$\mu_{22}^{q}$ & $\begin{array}{r}0.198 \\
(0.089)\end{array}$ & & $\begin{array}{l}-0.083 \\
(0.445)\end{array}$ & & $\begin{array}{l}-1.117 \\
(0.398)\end{array}$ & & $\begin{array}{r}-0.09 \\
(0.260)\end{array}$ & & $\begin{array}{l}-0.347 \\
(0.307)\end{array}$ & & $\begin{array}{r}-0.439 \\
(0.261)\end{array}$ & \\
\hline$\mu_{22}^{p}$ & $\begin{array}{l}-0.168 \\
(0.128)\end{array}$ & & $\begin{array}{r}0.033 \\
(0.342)\end{array}$ & & $\begin{array}{l}-0.267 \\
(0.282)\end{array}$ & & $\begin{array}{r}0.222 \\
(0.180)\end{array}$ & & $\begin{array}{r}-0.058 \\
(0.336)\end{array}$ & & $\begin{array}{r}0.563 \\
(0.365)\end{array}$ & \\
\hline$\phi_{11}$ & $\begin{array}{r}0.991 \\
(0.007)\end{array}$ & & $\begin{array}{r}0.941 \\
(0.025)\end{array}$ & & $\begin{array}{r}0.985 \\
(0.008)\end{array}$ & & $\begin{array}{r}0.976 \\
(0.011)\end{array}$ & & $\begin{array}{r}0.986 \\
(0.013)\end{array}$ & & $\begin{array}{r}0.981 \\
(0.010)\end{array}$ & \\
\hline$\phi_{22}$ & $\begin{array}{r}0.972 \\
(0.023)\end{array}$ & & $\begin{array}{r}0.844 \\
(0.056)\end{array}$ & & $\begin{array}{r}0.878 \\
(0.077)\end{array}$ & & $\begin{array}{r}0.893 \\
(0.058)\end{array}$ & & $\begin{array}{r}0.921 \\
(0.060)\end{array}$ & & $\begin{array}{r}0.873 \\
(0.066)\end{array}$ & \\
\hline$\Omega_{11}$ & $\begin{array}{r}0.578 \\
(0.047) \\
-0.067 \\
(0.049)\end{array}$ & $\begin{array}{r}-0.067 \\
(0.049) \\
0.241 \\
(0.025)\end{array}$ & $\begin{array}{r}3.062 \\
(0.308) \\
0.203 \\
(0.220)\end{array}$ & $\begin{array}{r}0.203 \\
(0.220) \\
0.775 \\
(0.085)\end{array}$ & $\begin{array}{r}2.852 \\
(0.227) \\
0.010 \\
(0.071)\end{array}$ & $\begin{array}{r}0.010 \\
(0.071) \\
0.141 \\
(0.012)\end{array}$ & $\begin{array}{r}1.549 \\
(0.136) \\
-0.038 \\
(0.060)\end{array}$ & $\begin{array}{r}-0.038 \\
(0.060) \\
0.148 \\
(0.014)\end{array}$ & $\begin{array}{r}0.916 \\
(0.083) \\
-0.095 \\
(0.074)\end{array}$ & $\begin{array}{r}-0.095 \\
(0.074) \\
0.262 \\
(0.024)\end{array}$ & $\begin{array}{r}0.611 \\
(0.052) \\
-0.030 \\
(0.036)\end{array}$ & $\begin{array}{r}-0.030 \\
(0.036) \\
0.169 \\
(0.014)\end{array}$ \\
\hline$\Omega_{22}$ & $\begin{array}{r}0.645 \\
(0.113) \\
-0.072 \\
(0.191)\end{array}$ & $\begin{array}{r}-0.072 \\
(0.191) \\
1.418 \\
(0.207)\end{array}$ & $\begin{array}{r}9.449 \\
(1.201) \\
3.889 \\
(1.595)\end{array}$ & $\begin{array}{r}3.889 \\
(1.595) \\
6.888 \\
(1.071)\end{array}$ & $\begin{array}{r}4.397 \\
(1.292) \\
-0.017 \\
(1.244)\end{array}$ & $\begin{array}{r}-0.017 \\
(1.244) \\
2.149 \\
(0.446)\end{array}$ & $\begin{array}{r}3.502 \\
(0.592) \\
-0.318 \\
(0.997)\end{array}$ & $\begin{array}{r}-0.318 \\
(0.997) \\
1.51 \\
(0.193)\end{array}$ & $\begin{array}{r}1.884 \\
(0.478) \\
-0.446 \\
(0.876)\end{array}$ & $\begin{array}{r}-0.446 \\
(0.876) \\
2.727 \\
(0.830)\end{array}$ & $\begin{array}{r}2.124 \\
(0.633) \\
-0.450 \\
(1.216)\end{array}$ & $\begin{array}{r}-0.450 \\
(1.216) \\
2.431 \\
(0.381)\end{array}$ \\
\hline
\end{tabular}

*Standard errors are in parentheses. 
Table III continued

\begin{tabular}{|c|c|c|c|c|c|c|c|c|c|c|c|c|}
\hline \multirow{3}{*}{$\begin{array}{l}\text { Parameter } \\
\mu_{11}^{q}\end{array}$} & \multicolumn{2}{|c|}{$\begin{array}{c}\text { Petroleum } \\
\text { Refining } \\
\text { (SIC 29) } \\
\end{array}$} & \multicolumn{2}{|c|}{$\begin{array}{l}\text { Rubber } \\
\text { (SIC 30) }\end{array}$} & \multicolumn{2}{|c|}{$\begin{array}{l}\text { Leather } \\
\text { (SIC 31) }\end{array}$} & \multicolumn{2}{|c|}{$\begin{array}{l}\text { Stone, Clay, } \\
\text { and Glass } \\
\text { (SIC 32) } \\
\end{array}$} & \multicolumn{2}{|c|}{$\begin{array}{l}\text { Nonferrous Metals } \\
\quad(\text { SIC33:3-6, 9) }\end{array}$} & \multicolumn{2}{|c|}{$\begin{array}{l}\text { Fabricated Metals } \\
\text { (SIC 34) }\end{array}$} \\
\hline & 0.276 & & 0.628 & & -0.239 & & 0.259 & & 0.476 & & 0.312 & \\
\hline & $(0.067) *$ & & $(0.095)$ & & $(0.099)$ & & $(0.102)$ & & $(0.137)$ & & $(0.068)$ & \\
\hline \multirow{2}{*}{$\mu_{11}^{p}$} & -0.046 & & -0.092 & & -0.003 & & 0.029 & & 0.627 & & 0.020 & \\
\hline & $(0.083)$ & & $(0.024)$ & & $(0.091)$ & & $(0.021)$ & & $(0.140)$ & & $(0.020)$ & \\
\hline \multirow{2}{*}{$\mu_{22}^{q}$} & -0.018 & & -0.044 & & -0.273 & & -0.673 & & -0.713 & & -0.727 & \\
\hline & $(0.131)$ & & $(0.655)$ & & $(0.200)$ & & $(0.360)$ & & $(0.378)$ & & $(0.221)$ & \\
\hline \multirow{2}{*}{$\mu_{22}^{p}$} & 0.218 & & 0.154 & & 0.238 & & -0.044 & & -1.272 & & 0.073 & \\
\hline & $(0.442)$ & & $(0.168)$ & & $(0.371)$ & & $(0.290)$ & & $(0.214)$ & & $(0.222)$ & \\
\hline$\phi_{11}$ & $\begin{array}{r}0.960 \\
(0.016)\end{array}$ & & $\begin{array}{r}0.969 \\
(0.012)\end{array}$ & & $\begin{array}{r}0.980 \\
(0.038)\end{array}$ & & $\begin{array}{r}0.983 \\
(0.009)\end{array}$ & & $\begin{array}{r}0.943 \\
(0.032)\end{array}$ & & $\begin{array}{r}0.984 \\
(0.007)\end{array}$ & \\
\hline$\phi_{22}$ & $\begin{array}{r}0.941 \\
(0.022)\end{array}$ & & $\begin{array}{r}0.874 \\
(0.054)\end{array}$ & & $\begin{array}{r}0.948 \\
(0.047)\end{array}$ & & $\begin{array}{r}0.876 \\
(0.066)\end{array}$ & & $\begin{array}{r}0.879 \\
(0.059)\end{array}$ & & $\begin{array}{r}0.896 \\
(0.066)\end{array}$ & \\
\hline \multirow[t]{2}{*}{$\Omega_{11}$} & 1.043 & 0.131 & 2.714 & -0.064 & 1.812 & -0.031 & 3.159 & 0.040 & 2.941 & -0.086 & 1.408 & 0.000 \\
\hline & $\begin{array}{r}(0.091) \\
0.131 \\
(0.188)\end{array}$ & $\begin{array}{r}(0.188) \\
1.581 \\
(0.146)\end{array}$ & $\begin{array}{r}(0.247) \\
-0.064 \\
(0.083)\end{array}$ & $\begin{array}{r}(0.083) \\
0.167 \\
(0.015)\end{array}$ & $\begin{array}{c}(0.172) \\
-0.031 \\
(0.243)\end{array}$ & $\begin{array}{r}(0.243) \\
1.446 \\
(0.180)\end{array}$ & $\begin{array}{r}(0.185) \\
0.040 \\
(0.079)\end{array}$ & $\begin{array}{r}(0.079) \\
0.144 \\
(0.012)\end{array}$ & $\begin{array}{r}(0.368) \\
-0.086 \\
(0.477)\end{array}$ & $\begin{array}{r}(0.477) \\
2.069 \\
(0.191)\end{array}$ & $\begin{array}{r}(0.106) \\
0.000 \\
(0.051)\end{array}$ & $\begin{array}{r}(0.051) \\
0.134 \\
(0.011)\end{array}$ \\
\hline$\Omega_{22}$ & $\begin{array}{r}2.192 \\
(0.244) \\
-0.217 \\
(1.489) \\
\end{array}$ & $\begin{array}{l}-0.217 \\
(1.489) \\
24.796 \\
(2.375) \\
\end{array}$ & $\begin{array}{r}18.474 \\
(2.388) \\
0.112 \\
(2.444) \\
\end{array}$ & $\begin{array}{r}0.112 \\
(2.444) \\
1.587 \\
(0.170) \\
\end{array}$ & $\begin{array}{r}4.039 \\
(0.531) \\
0.429 \\
(2.042) \\
\end{array}$ & $\begin{array}{r}0.429 \\
(2.042) \\
15.310 \\
(1.542) \\
\end{array}$ & $\begin{array}{r}4.222 \\
(1.000) \\
-0.433 \\
(1.776) \\
\end{array}$ & $\begin{array}{r}-0.433 \\
(1.776) \\
2.063 \\
(0.428) \\
\end{array}$ & $\begin{array}{r}8.816 \\
(1.887) \\
-0.092 \\
(1.252) \\
\end{array}$ & $\begin{array}{r}-0.092 \\
(1.252) \\
1.915 \\
(0.254) \\
\end{array}$ & $\begin{array}{r}2.244 \\
(0.465) \\
-0.212 \\
(0.970) \\
\end{array}$ & $\begin{array}{r}-0.212 \\
(0.970) \\
2.469 \\
(0.380) \\
\end{array}$ \\
\hline
\end{tabular}

*Standard errors are in parentheses. 
Table III continued

\begin{tabular}{|c|c|c|c|c|c|c|c|c|c|c|}
\hline \multirow{3}{*}{$\begin{array}{l}\text { Parameter } \\
\mu_{11}^{q}\end{array}$} & \multicolumn{2}{|c|}{$\begin{array}{l}\text { Agricultural } \\
\text { Machinery } \\
\text { (SIC 352) } \\
\end{array}$} & \multicolumn{2}{|c|}{$\begin{array}{c}\text { Construction } \\
\text { Machinery } \\
\text { (SIC 353) }\end{array}$} & \multicolumn{2}{|c|}{$\begin{array}{c}\text { Metalworking } \\
\text { Machinery } \\
\text { (SIC 354) } \\
\end{array}$} & \multicolumn{2}{|c|}{$\begin{array}{c}\text { Electrical } \\
\text { Machinery } \\
\text { (SIC 36) } \\
\end{array}$} & \multicolumn{2}{|c|}{$\begin{array}{c}\text { Transportation } \\
\text { Equipment } \\
\text { (SIC 37) } \\
\end{array}$} \\
\hline & 0.490 & & 0.400 & & 0.125 & & 0.604 & & 0.329 & \\
\hline & $(0.192)$ & & $(0.092)$ & & $(0.133)$ & & $(0.080)$ & & $(0.173)$ & \\
\hline$\mu_{1}^{p}$ & 0.036 & & 0.051 & & 0.053 & & -0.071 & & 0.036 & \\
\hline & $(0.034)$ & & $(0.029)$ & & $(0.036)$ & & $(0.021)$ & & $(0.028)$ & \\
\hline$\mu_{22}^{q}$ & -1.088 & & -1.369 & & -0.641 & & -0.297 & & -0.393 & \\
\hline & $(0.543)$ & & $(0.364)$ & & $(0.347)$ & & $(0.336)$ & & $(0.980)$ & \\
\hline$\mu_{22}^{p}$ & 0.084 & & 0.156 & & 0.121 & & -0.122 & & -0.176 & \\
\hline & (0.199) & & $(0.293)$ & & $(0.277)$ & & $(0.307)$ & & $(0.213)$ & \\
\hline$\phi_{11}$ & $\begin{array}{r}0.962 \\
(0.019)\end{array}$ & & $\begin{array}{r}0.976 \\
(0.014)\end{array}$ & & $\begin{array}{r}0.988 \\
(0.050)\end{array}$ & & $\begin{array}{r}0.987 \\
(0.007)\end{array}$ & & $\begin{array}{r}0.965 \\
(0.018)\end{array}$ & \\
\hline$\phi_{22}$ & $\begin{array}{r}0.893 \\
(0.063)\end{array}$ & & $\begin{array}{r}0.897 \\
(0.060)\end{array}$ & & $\begin{array}{r}0.913 \\
(0.042)\end{array}$ & & $\begin{array}{r}0.89 \\
(0.080)\end{array}$ & & $\begin{array}{r}0.87 \\
(0.070)\end{array}$ & \\
\hline$\Omega_{11}$ & 5.629 & 0.066 & 1.964 & -0.024 & 3.737 & -0.062 & 1.892 & -0.027 & 5.291 & -0.033 \\
\hline & $\begin{array}{r}(0.640) \\
0.066 \\
(0.167)\end{array}$ & $\begin{array}{r}(0.167) \\
0.168 \\
(0.023)\end{array}$ & $\begin{array}{r}(0.170) \\
-0.024 \\
(0.086)\end{array}$ & $\begin{array}{r}(0.086) \\
0.204 \\
(0.018)\end{array}$ & $\begin{array}{r}(0.373) \\
-0.062 \\
(0.131)\end{array}$ & $\begin{array}{r}(0.131) \\
0.168 \\
(0.021)\end{array}$ & $\begin{array}{r}(0.153) \\
-0.027 \\
(0.059)\end{array}$ & $\begin{array}{r}(0.059) \\
0.146 \\
(0.012)\end{array}$ & $\begin{array}{l}(0.528) \\
-0.033 \\
(0.130)\end{array}$ & $\begin{array}{r}(0.130) \\
0.16 \\
(0.016)\end{array}$ \\
\hline$\Omega_{22}$ & $\begin{array}{r}14.529 \\
(3.347) \\
-0.439 \\
(1.802) \\
\end{array}$ & $\begin{array}{r}-0.439 \\
(1.802) \\
1.620 \\
(0.216) \\
\end{array}$ & $\begin{array}{r}5.957 \\
(0.969) \\
-0.746 \\
(1.796) \\
\end{array}$ & $\begin{array}{r}-0.746 \\
(1.796) \\
2.481 \\
(0.330) \\
\end{array}$ & $\begin{array}{r}4.723 \\
(1.099) \\
-1.290 \\
(0.968) \\
\end{array}$ & $\begin{array}{r}-1.290 \\
(0.968) \\
2.341 \\
(0.479) \\
\end{array}$ & $\begin{array}{r}3.507 \\
(0.915) \\
-0.416 \\
(1.173) \\
\end{array}$ & $\begin{array}{r}-0.416 \\
(1.173) \\
2.321 \\
(0.459) \\
\end{array}$ & $\begin{array}{r}23.141 \\
(3.587) \\
0.026 \\
(3.024) \\
\end{array}$ & $\begin{array}{r}0.026 \\
(3.024) \\
1.736 \\
(0.388) \\
\end{array}$ \\
\hline
\end{tabular}


Table IV

Tests of Different Means across Regimes

\begin{tabular}{|c|c|c|c|c|}
\hline \multirow[t]{2}{*}{ Industry } & \multicolumn{2}{|c|}{$\begin{array}{c}\mathrm{H}_{0}: \mu_{1}^{q}=\mu_{2}^{q} \\
\mathrm{H}_{\mathrm{a}}: \mu_{1}^{q} \neq \mu_{2}^{q}\end{array}$} & \multicolumn{2}{|c|}{$\begin{array}{c}\mathrm{H}_{0}: \mu_{1}^{p}=\mu_{2}^{p} \\
\mathrm{H}_{\mathrm{a}}: \mu_{1}^{p} \neq \mu_{2}^{p}\end{array}$} \\
\hline & Wald Test & $p$-value & Wald Test & $p$-value \\
\hline Food (SIC 20) & 0.046 & $(0.830)$ & 2.832 & $(0.092)$ \\
\hline Lumber (SIC 24) & 0.930 & $(0.335)$ & 0.002 & $(0.969)$ \\
\hline Furniture (SIC 25) & 14.039 & $(0.000)$ & 1.165 & $(0.280)$ \\
\hline Paper (SIC 26) & 2.006 & $(0.157)$ & 0.951 & $(0.329)$ \\
\hline Newspaper (SIC 271) & 2.822 & $(0.093)$ & 0.530 & $(0.467)$ \\
\hline Chemicals (SIC 28) & 19.296 & $(0.000)$ & 7.836 & $(\mathbf{0 . 0 0 5 )}$ \\
\hline Petroleum Refining (SIC 29) & 3.674 & $(\mathbf{0 . 0 5 5 )}$ & 0.408 & $(0.523)$ \\
\hline Rubber (SIC 30) & 2.638 & $(0.104)$ & 0.445 & $(0.504)$ \\
\hline Leather (SIC 31) & 0.007 & $(0.933)$ & 0.796 & $(0.372)$ \\
\hline Stone, Clay, and Glass (SIC 32) & 7.619 & $(0.006)$ & 0.261 & $(0.610)$ \\
\hline Nonferrous Metals (SIC 33:3-6, 9) & 11.179 & $(0.001)$ & 77.682 & $(\mathbf{0 . 0 0 0 )}$ \\
\hline Fabricated Metals (SIC 34) & 15.873 & $(0.000)$ & 0.008 & $(0.930)$ \\
\hline Agricultural Machinery (SIC 352) & 8.881 & $(0.003)$ & 0.047 & $(0.828)$ \\
\hline Construction Machinery (SIC 353) & 23.928 & $(0.000)$ & 0.195 & $(0.659)$ \\
\hline Metalworking Machinery (SIC 354) & 2.495 & $(0.114)$ & 0.016 & $(0.899)$ \\
\hline Electrical Machinery (SIC 36) & 7.764 & $(0.005)$ & 0.085 & $(0.771)$ \\
\hline Transportation Equipment (SIC 37) & 1.982 & $(0.159)$ & 1.197 & $(0.274)$ \\
\hline
\end{tabular}

Note: Statistics are asymptotically $\chi_{1}^{2}$. Asymptotic $p$-values less than .1 are in bold. 
Table V

Test of Different Price Variances Across Regimes

\begin{tabular}{|c|c|c|c|}
\hline \multirow[t]{2}{*}{ Industry } & \multicolumn{2}{|c|}{$\begin{array}{l}\mathrm{H}_{0}: \sigma_{1, p}^{2}=\sigma_{2, p}^{2} \\
\mathrm{H}_{\mathrm{a}}: \sigma_{1, p}^{2} \neq \sigma_{2, p}^{2}\end{array}$} & \multirow{2}{*}{$\frac{\hat{\sigma}_{2, p}^{2}{ }^{*}}{\hat{\sigma}_{1, p}^{2}}$} \\
\hline & $\begin{array}{c}\text { Likelihood } \\
\text { Ratio Test }\end{array}$ & $p$-value & \\
\hline Food (SIC 20) & 68.274 & $(0.000)$ & 5.86 \\
\hline Lumber (SIC 24) & 109.508 & $(0.000)$ & 8.14 \\
\hline Furniture (SIC 25) & 142.410 & $(0.000)$ & 14.38 \\
\hline Paper (SIC 26) & 144.794 & $(0.000)$ & 9.84 \\
\hline Newspaper (SIC 271) & 99.566 & $(0.000)$ & 9.91 \\
\hline Chemicals (SIC 28) & 421.102 & $(0.000)$ & 13.32 \\
\hline Petroleum Refining (SIC 29) & 256.162 & $(0.000)$ & 15.15 \\
\hline Rubber (SIC 30) & 149.436 & $(0.000)$ & 8.88 \\
\hline Leather (SIC 31) & 219.260 & $(0.000)$ & 10.36 \\
\hline Stone, Clay, and Glass (SIC 32) & 169.534 & $(0.000)$ & 13.68 \\
\hline Nonferrous Metals (SIC 33:3-6, 9) & 0.002 & $(0.964)$ & 1.01 \\
\hline Fabricated Metals (SIC 34) & 292.092 & $(0.000)$ & 17.65 \\
\hline Agricultural Machinery (SIC 352) & 103.262 & $(0.000)$ & 9.23 \\
\hline Construction Machinery (SIC 353) & 121.596 & $(0.000)$ & 11.61 \\
\hline Metalworking Machinery (SIC 354) & 119.200 & $(0.000)$ & 13.54 \\
\hline Electrical Machinery (SIC 36) & 201.972 & $(0.000)$ & 15.20 \\
\hline Transportation Equipment (SIC 37) & 144.254 & $(0.000)$ & 10.29 \\
\hline
\end{tabular}

Note: Statistics are asymptotically $\chi_{1}^{2}$. Asymptotic $p$-values less than .1 are in bold.

* Both the restricted and the unrestricted likelihood functions were estimated without the Bayesian correction. 
Table VI

Conditional Moment Normality Tests (Skewness and Kurtosis)*

\begin{tabular}{|c|c|c|c|c|c|}
\hline $\begin{array}{r}\text { Test: } \\
\text { Variable: }\end{array}$ & $\begin{array}{c}\text { Joint Test of } \\
\text { Normality } \\
\mathbf{y}_{t}\end{array}$ & $\begin{array}{c}\text { Skewness } \\
q_{t}\end{array}$ & $\begin{array}{c}\text { Skewness } \\
p_{t}\end{array}$ & $\begin{array}{c}\text { Kurtosis } \\
q_{t}\end{array}$ & $\begin{array}{c}\text { Kurtosis } \\
p_{t}\end{array}$ \\
\hline Food (SIC 20) & $\begin{array}{c}2.459 \\
(0.652)\end{array}$ & $\begin{array}{c}0.271 \\
(0.603)\end{array}$ & $\begin{array}{c}1.228 \\
(0.268)\end{array}$ & $\begin{array}{c}0.113 \\
(0.736)\end{array}$ & $\begin{array}{c}0.123 \\
(0.726)\end{array}$ \\
\hline Lumber (SIC 24) & $\begin{array}{l}56.538 \\
(\mathbf{0 . 0 0 0 )}\end{array}$ & $\begin{array}{c}1.844 \\
(0.175)\end{array}$ & $\begin{array}{l}23.516 \\
(\mathbf{0 . 0 0 0 )}\end{array}$ & $\begin{array}{c}4.696 \\
(\mathbf{0 . 0 3 0})\end{array}$ & $\begin{array}{c}4.023 \\
(\mathbf{0 . 0 4 5 )}\end{array}$ \\
\hline Furniture (SIC 25) & $\begin{array}{r}18.922 \\
\mathbf{( 0 . 0 0 1 )}\end{array}$ & $\begin{array}{c}0.312 \\
(0.577)\end{array}$ & $\begin{array}{c}7.439 \\
(\mathbf{0 . 0 0 6})\end{array}$ & $\begin{array}{c}2.550 \\
(0.110)\end{array}$ & $\begin{array}{c}1.962 \\
(0.161)\end{array}$ \\
\hline Paper (SIC 26) & $\begin{array}{c}8.984 \\
(\mathbf{0 . 0 6 2})\end{array}$ & $\begin{array}{c}3.222 \\
(\mathbf{0 . 0 7 3 )}\end{array}$ & $\begin{array}{c}4.427 \\
(\mathbf{0 . 0 3 5 )}\end{array}$ & $\begin{array}{c}4.085 \\
(\mathbf{0 . 0 4 3 )}\end{array}$ & $\begin{array}{c}3.397 \\
(\mathbf{0 . 0 6 5 )}\end{array}$ \\
\hline Newspaper (SIC 271) & $\begin{array}{c}15.823 \\
(\mathbf{0 . 0 0 3 )}\end{array}$ & $\begin{array}{c}2.181 \\
(0.140)\end{array}$ & $\begin{array}{c}10.625 \\
(\mathbf{0 . 0 0 1 )}\end{array}$ & $\begin{array}{c}3.697 \\
(\mathbf{0 . 0 5 5})\end{array}$ & $\begin{array}{c}2.993 \\
(\mathbf{0 . 0 8 4 )}\end{array}$ \\
\hline Chemicals (SIC 28) & $\begin{array}{r}10.670 \\
(\mathbf{0 . 0 3 1 )}\end{array}$ & $\begin{array}{c}4.349 \\
(\mathbf{0 . 0 3 7})\end{array}$ & $\begin{array}{c}2.088 \\
(0.149)\end{array}$ & $\begin{array}{c}0.309 \\
(0.578)\end{array}$ & $\begin{array}{c}4.218 \\
(\mathbf{0 . 0 4 0 )}\end{array}$ \\
\hline Petroleum Refining (SIC 29) & $\begin{array}{r}10.007 \\
\mathbf{( 0 . 0 4 0 )}\end{array}$ & $\begin{array}{c}0.003 \\
(0.959)\end{array}$ & $\begin{array}{c}1.656 \\
(0.198)\end{array}$ & $\begin{array}{c}2.084 \\
(0.149)\end{array}$ & $\begin{array}{c}8.345 \\
(\mathbf{0 . 0 0 4 )}\end{array}$ \\
\hline Rubber (SIC 30) & $\begin{array}{l}23.788 \\
(\mathbf{0 . 0 0 0 )}\end{array}$ & $\begin{array}{r}12.757 \\
(\mathbf{0 . 0 0 0 )}\end{array}$ & $\begin{array}{c}3.774 \\
(\mathbf{0 . 0 5 2})\end{array}$ & $\begin{array}{l}12.229 \\
(\mathbf{0 . 0 0 1 )}\end{array}$ & $\begin{array}{c}5.255 \\
(\mathbf{0 . 0 2 2})\end{array}$ \\
\hline Leather (SIC 31) & $\begin{array}{c}9.241 \\
(\mathbf{0 . 0 5 5})\end{array}$ & $\begin{array}{c}3.682 \\
(\mathbf{0 . 0 5 5})\end{array}$ & $\begin{array}{c}0.768 \\
(0.381)\end{array}$ & $\begin{array}{c}2.003 \\
(0.157)\end{array}$ & $\begin{array}{c}4.556 \\
(\mathbf{0 . 0 3 3})\end{array}$ \\
\hline Stone, Clay, and Glass (SIC 32) & $\begin{array}{l}54.066 \\
\mathbf{( 0 . 0 0 0 )}\end{array}$ & $\begin{array}{c}2.474 \\
(0.116)\end{array}$ & $\begin{array}{r}18.137 \\
\mathbf{( 0 . 0 0 0 )}\end{array}$ & $\begin{array}{c}7.921 \\
(\mathbf{0 . 0 0 5})\end{array}$ & $\begin{array}{c}5.938 \\
(\mathbf{0 . 0 1 5})\end{array}$ \\
\hline Nonferrous Metals (SIC 33:3-6, 9) & $\begin{array}{l}24.333 \\
\mathbf{( 0 . 0 0 0 )}\end{array}$ & $\begin{array}{c}0.279 \\
(0.598)\end{array}$ & $\begin{array}{c}0.242 \\
(0.623)\end{array}$ & $\begin{array}{c}0.168 \\
(0.682)\end{array}$ & $\begin{array}{l}23.606 \\
\mathbf{( 0 . 0 0 0 )}\end{array}$ \\
\hline Fabricated Metals (SIC 34) & $\begin{array}{r}10.023 \\
(\mathbf{0 . 0 4 0 )}\end{array}$ & $\begin{array}{c}0.107 \\
(0.744)\end{array}$ & $\begin{array}{c}0.107 \\
(0.744)\end{array}$ & $\begin{array}{c}6.800 \\
(\mathbf{0 . 0 0 9})\end{array}$ & $\begin{array}{c}3.993 \\
(\mathbf{0 . 0 4 6 )}\end{array}$ \\
\hline Agricultural Machinery (SIC 352) & $\begin{array}{l}22.579 \\
(\mathbf{0 . 0 0 0 )}\end{array}$ & $\begin{array}{c}1.473 \\
(0.225)\end{array}$ & $\begin{array}{r}10.208 \\
(\mathbf{0 . 0 0 1})\end{array}$ & $\begin{array}{c}0.478 \\
(0.489)\end{array}$ & $\begin{array}{c}4.401 \\
(\mathbf{0 . 0 3 6 )}\end{array}$ \\
\hline Construction Machinery (SIC 353) & $\begin{array}{l}22.526 \\
(\mathbf{0 . 0 0 0 )}\end{array}$ & $\begin{array}{c}5.128 \\
(\mathbf{0 . 0 2 4})\end{array}$ & $\begin{array}{c}0.042 \\
(0.838)\end{array}$ & $\begin{array}{c}3.501 \\
(\mathbf{0 . 0 6 1 )}\end{array}$ & $\begin{array}{r}14.826 \\
\mathbf{( 0 . 0 0 0 )}\end{array}$ \\
\hline Metalworking Machinery (SIC 354) & $\begin{array}{l}22.620 \\
\mathbf{( 0 . 0 0 0 )}\end{array}$ & $\begin{array}{c}1.076 \\
(0.300)\end{array}$ & $\begin{array}{c}9.348 \\
(\mathbf{0 . 0 0 2})\end{array}$ & $\begin{array}{c}0.055 \\
(0.814)\end{array}$ & $\begin{array}{c}2.626 \\
(0.105)\end{array}$ \\
\hline Electrical Machinery (SIC 36) & $\begin{array}{l}44.848 \\
\mathbf{( 0 . 0 0 0 )}\end{array}$ & $\begin{array}{c}3.755 \\
(\mathbf{0 . 0 5 3})\end{array}$ & $\begin{array}{r}15.090 \\
(\mathbf{0 . 0 0 0})\end{array}$ & $\begin{array}{c}1.693 \\
(0.193)\end{array}$ & $\begin{array}{c}3.317 \\
(\mathbf{0 . 0 6 9 )}\end{array}$ \\
\hline Transportation Equipment (SIC 37) & $\begin{array}{l}36.802 \\
\mathbf{( 0 . 0 0 0 )}\end{array}$ & $\begin{array}{c}1.288 \\
(0.256)\end{array}$ & $\begin{array}{r}11.152 \\
\mathbf{( 0 . 0 0 1 )}\end{array}$ & $\begin{array}{c}9.713 \\
(\mathbf{0 . 0 0 2})\end{array}$ & $\begin{array}{c}3.963 \\
\mathbf{( 0 . 0 4 7 )}\end{array}$ \\
\hline
\end{tabular}

Note: Column 2 statistics are asymptotically $\chi_{4}^{2}$. Statistics in columns 3-6 are asymptotically $\chi_{1}^{2}$. Asymptotic $p$-values less than .1 are in bold.

* The maximum likelihood estimates used in the calculations of the score were estimated without the Bayesian correction. 
Table VII

Response of Price Changes to Changes in Manufacturing Capacity Utilization

\begin{tabular}{lcc}
\hline & $(1)$ & $(2)$ \\
\hline Utilization Change $\left(\Delta z_{t}\right)$ & 0.061 & 0.048 \\
& $(0.022)$ & $(0.020)$ \\
Lagged Price Change $\left(p_{j, t-1}\right)$ & & 0.416 \\
& & $(0.011)$ \\
\hline Adjusted R ${ }^{2}$ & 0.0013 & 0.1739 \\
\# Observations & 6,710 & 6,693 \\
\hline Note: Coefficient estimates for industry dummy variables are not reported. Standard errors are in parantheses.
\end{tabular}


Figure 1

Capacity Regions for the Pricing Subgame

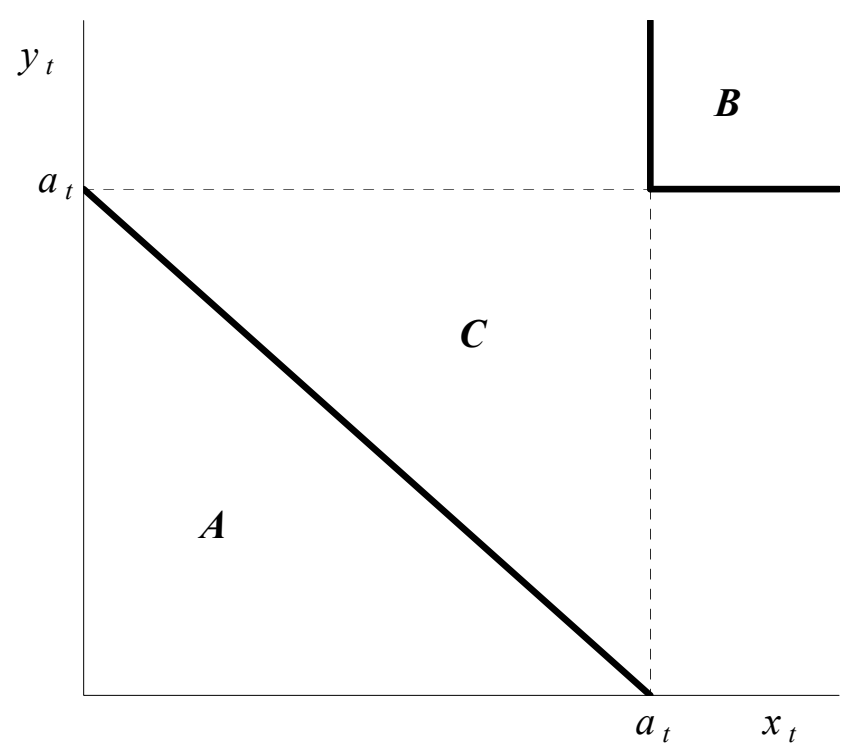

$$
\begin{aligned}
& A=\left\{\left(x_{t}, y_{t}\right): x_{t} \geq 0, y_{t} \geq 0, x_{t}+y_{t} \leq a_{t}\right\} \\
& B=\left\{\left(x_{t}, y_{t}\right): x_{t} \geq a_{t}, y_{t} \geq a_{t}\right\} \\
& C=\left\{\left(x_{t}, y_{t}\right): x_{t} \geq 0, y_{t} \geq 0,\left(x_{t}, y_{t}\right) \notin A,\left(x_{t}, y_{t}\right) \notin B\right\}
\end{aligned}
$$


Figure 2A

Equilibrium Capacity Choices

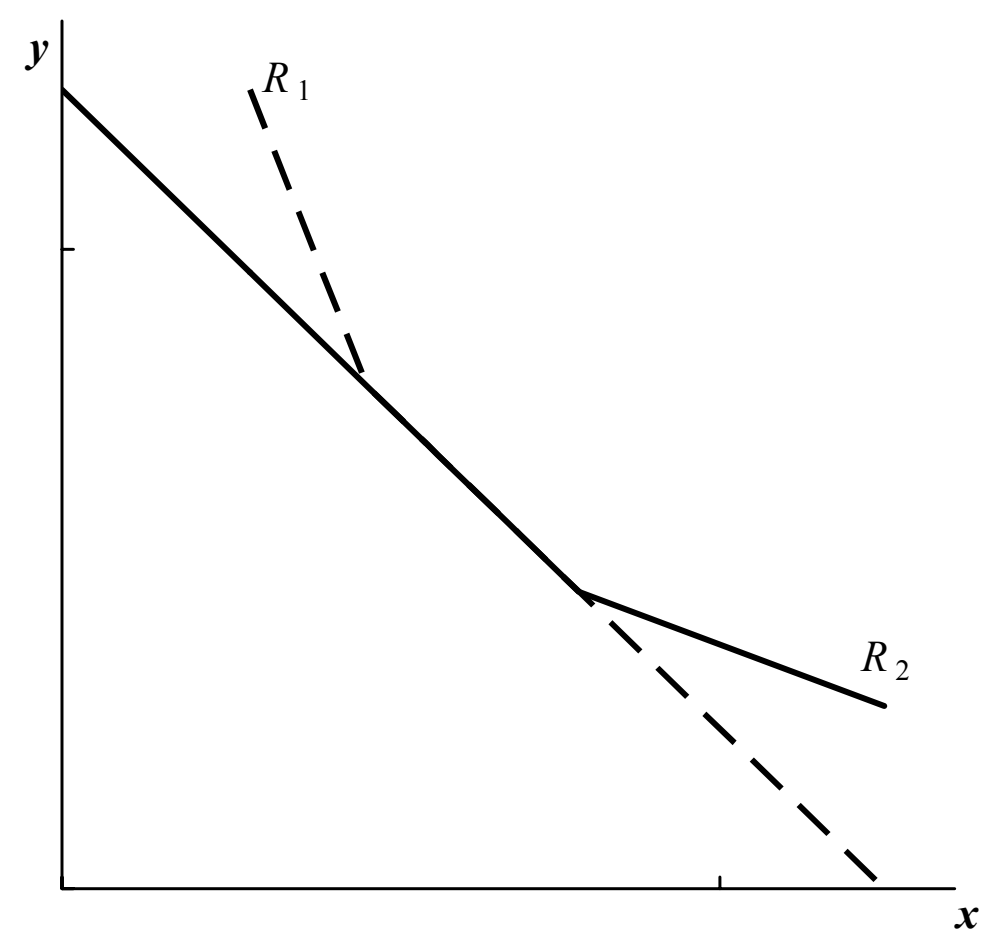

Parameter Values : $\phi_{s_{1-1}, 2}=1 / 2, c / v=1 / 4, \tau_{2}=5 / 4 \tau_{1}$

Figure 2B

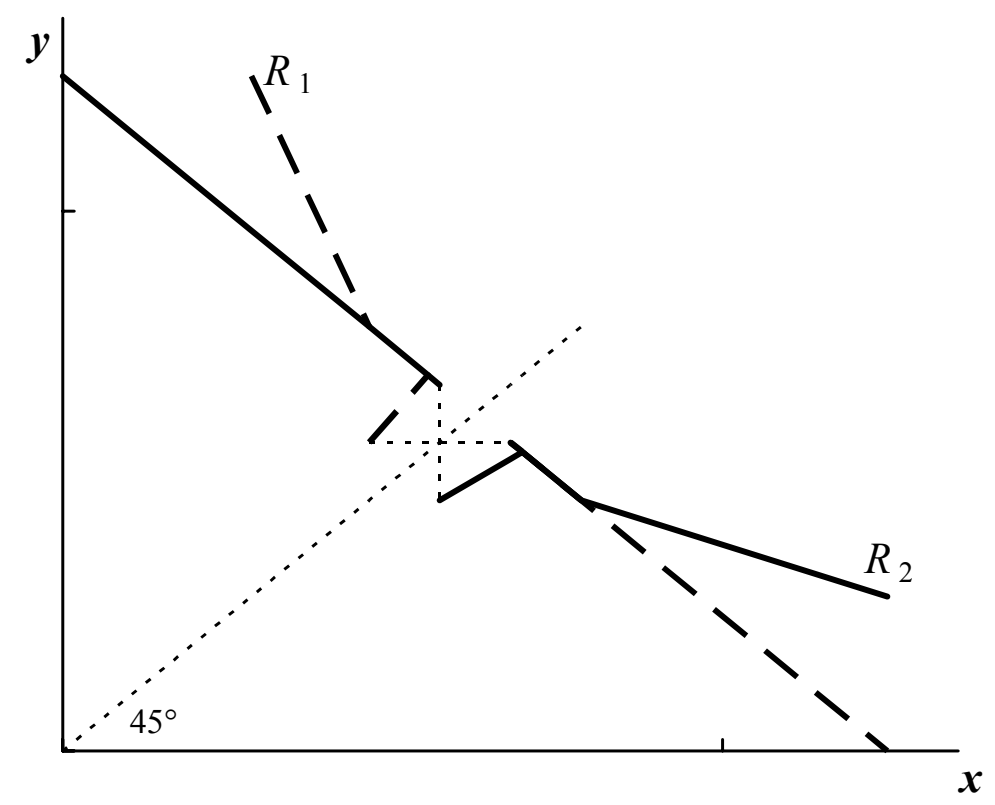

Parameter Values : $\phi_{\mathrm{s}_{\mathrm{t}-1}, 2}=3 / 4, c / v=1 / 8, \tau_{2}=5 / 4 \tau_{1}$ 
Figure 3

Equilibrium Mixing Distributions

$\phi_{i, 2}=1 / 2, \quad c / v=1 / 3, \quad \tau_{2}=5 / 4 \tau_{1}$

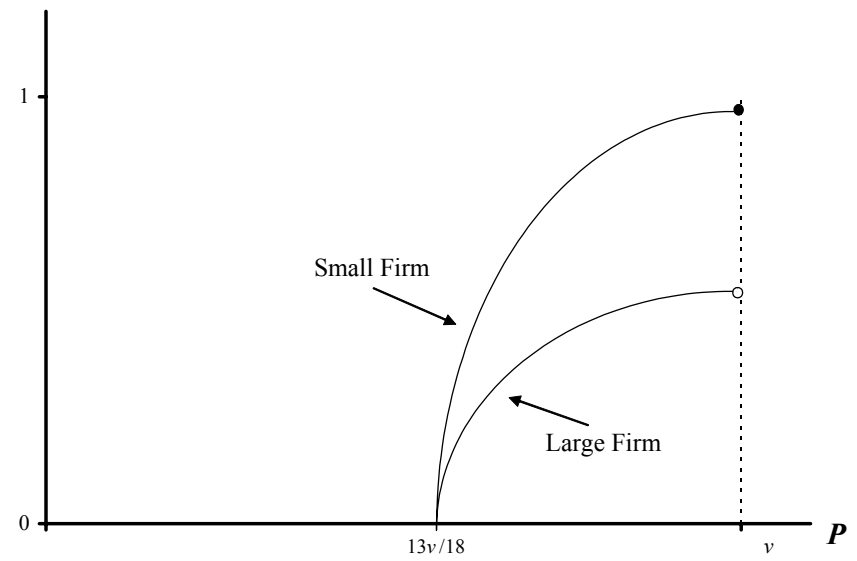


Figure 4a

Inferred Probability of Being in State 2 (Recessionary State)
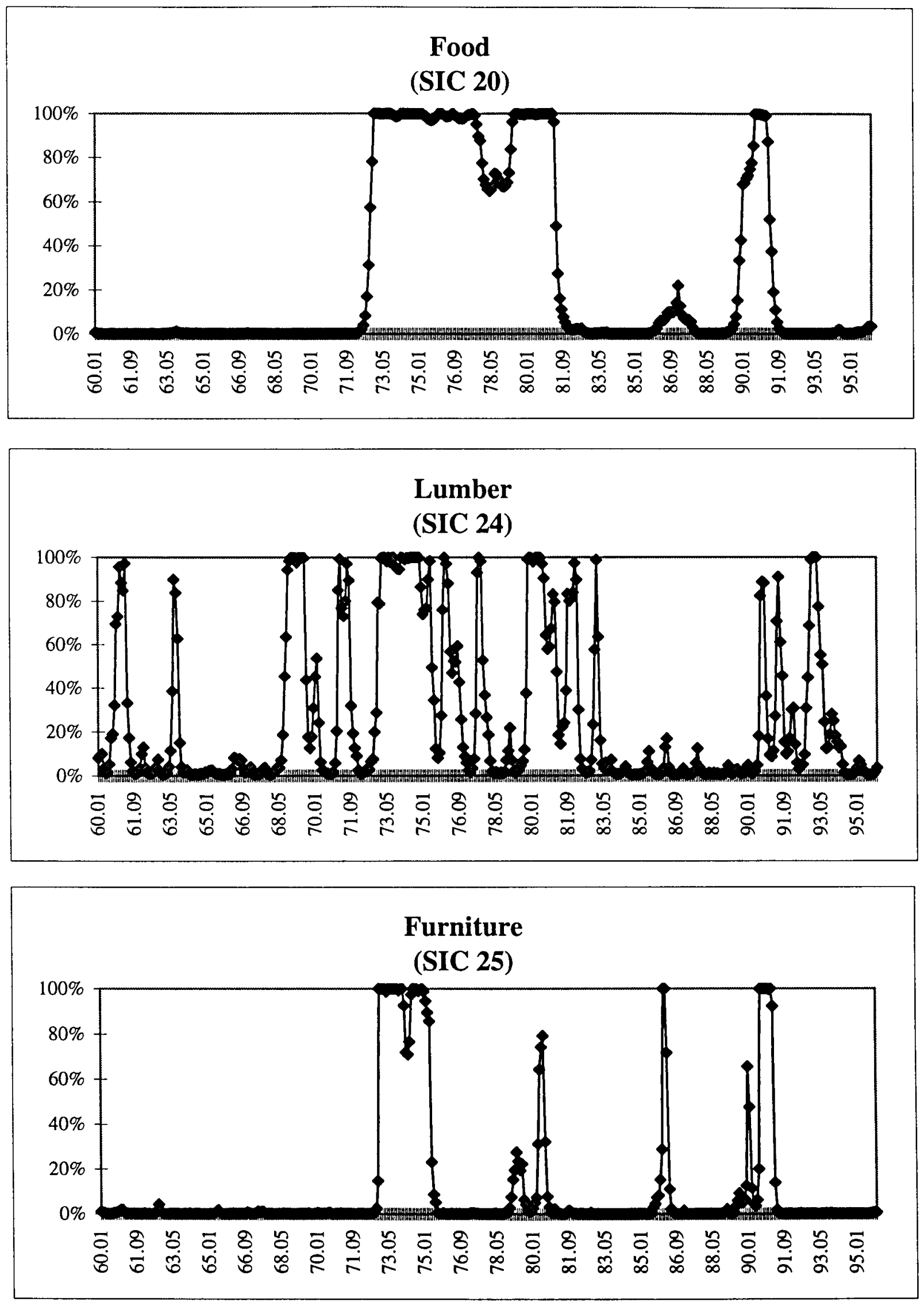
Figure 4b

Inferred Probability of Being in State 2 (Recessionary State)
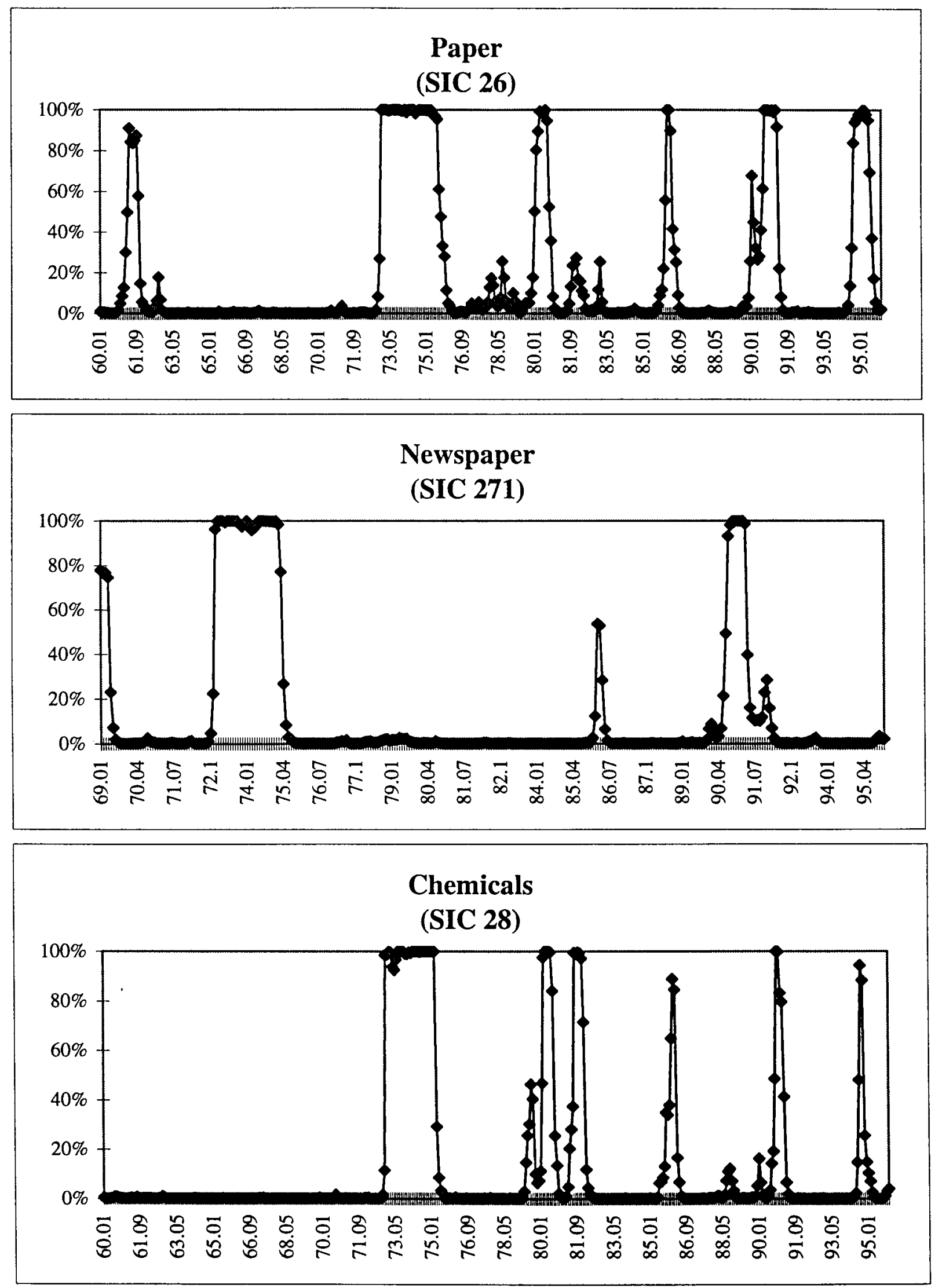
Figure 4c

Inferred Probability of Being in State 2 (Recessionary State)
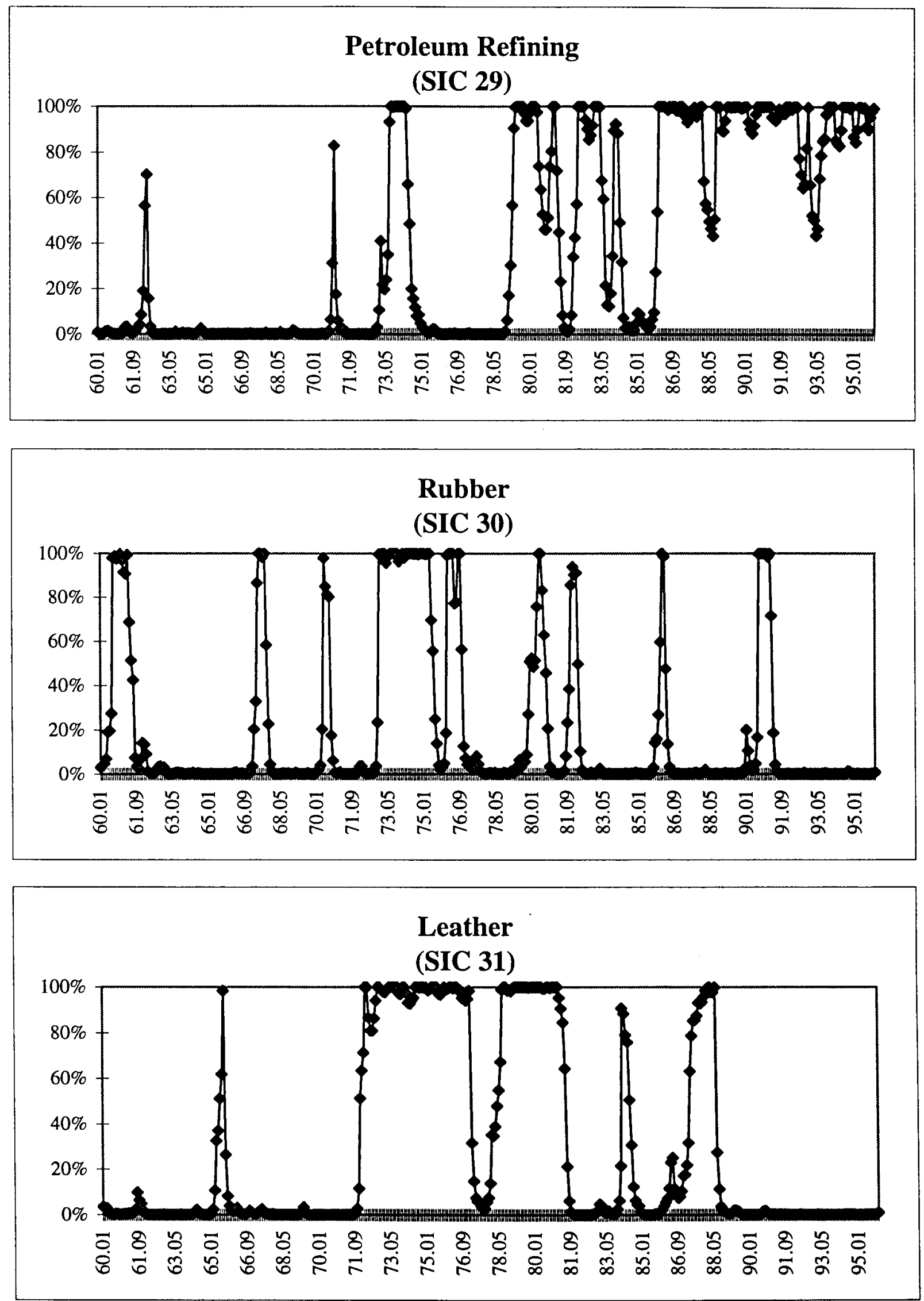
Figure 4d

Inferred Probability of Being in State 2 (Recessionary State)
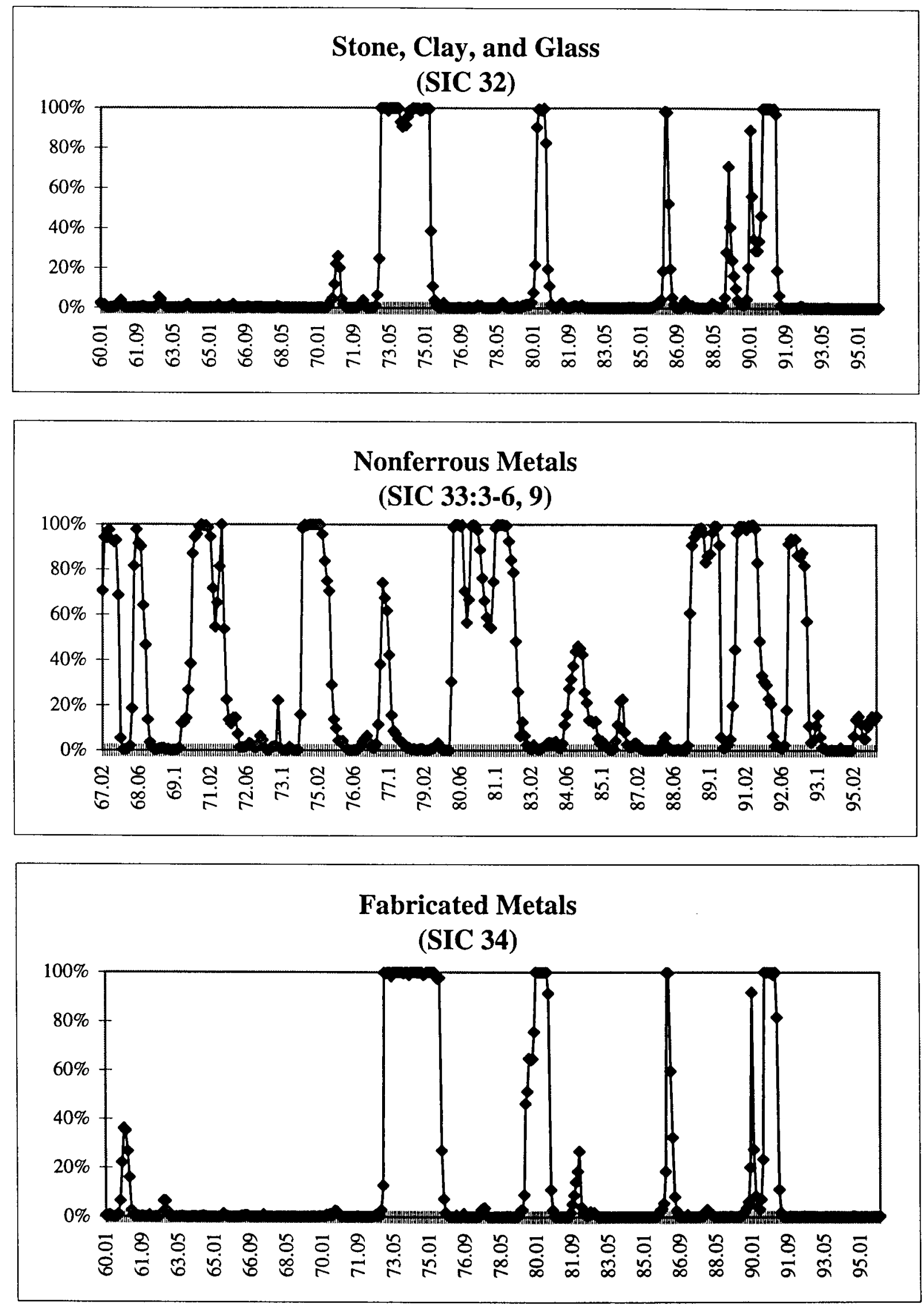
Figure 4e

Inferred Probability of Being in State 2 (Recessionary State)
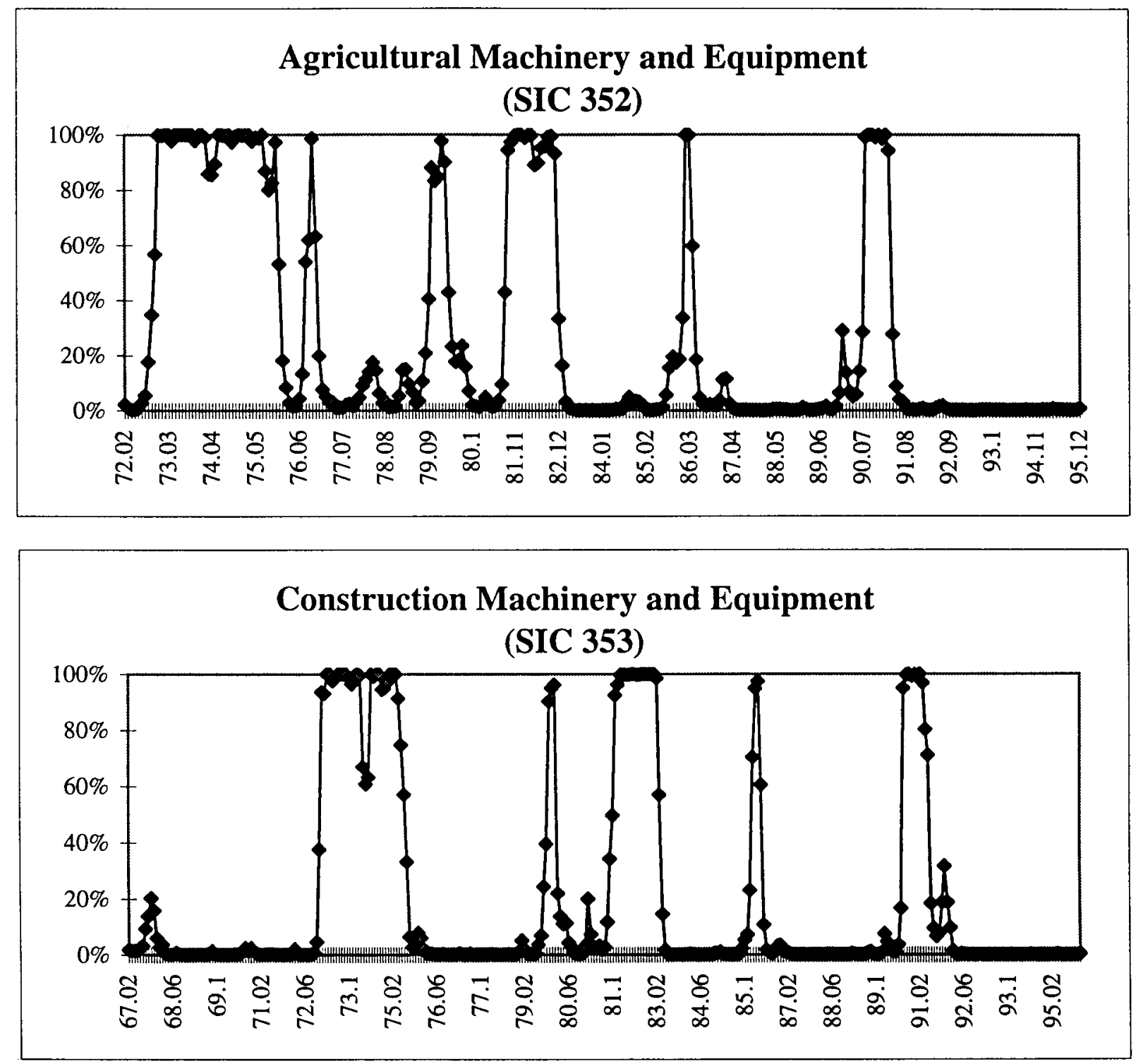

Metalworking Machinery and Equipment

(SIC 354)

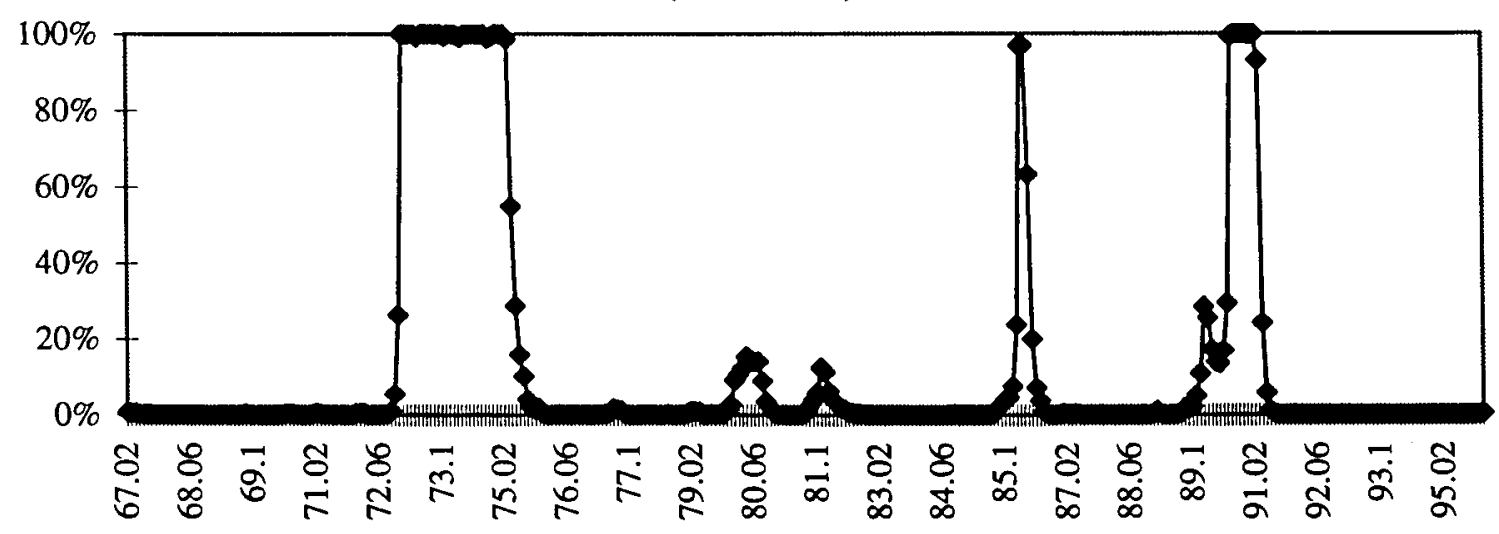


Figure 4f

Inferred Probability of Being in State 2 (Recessionary State)
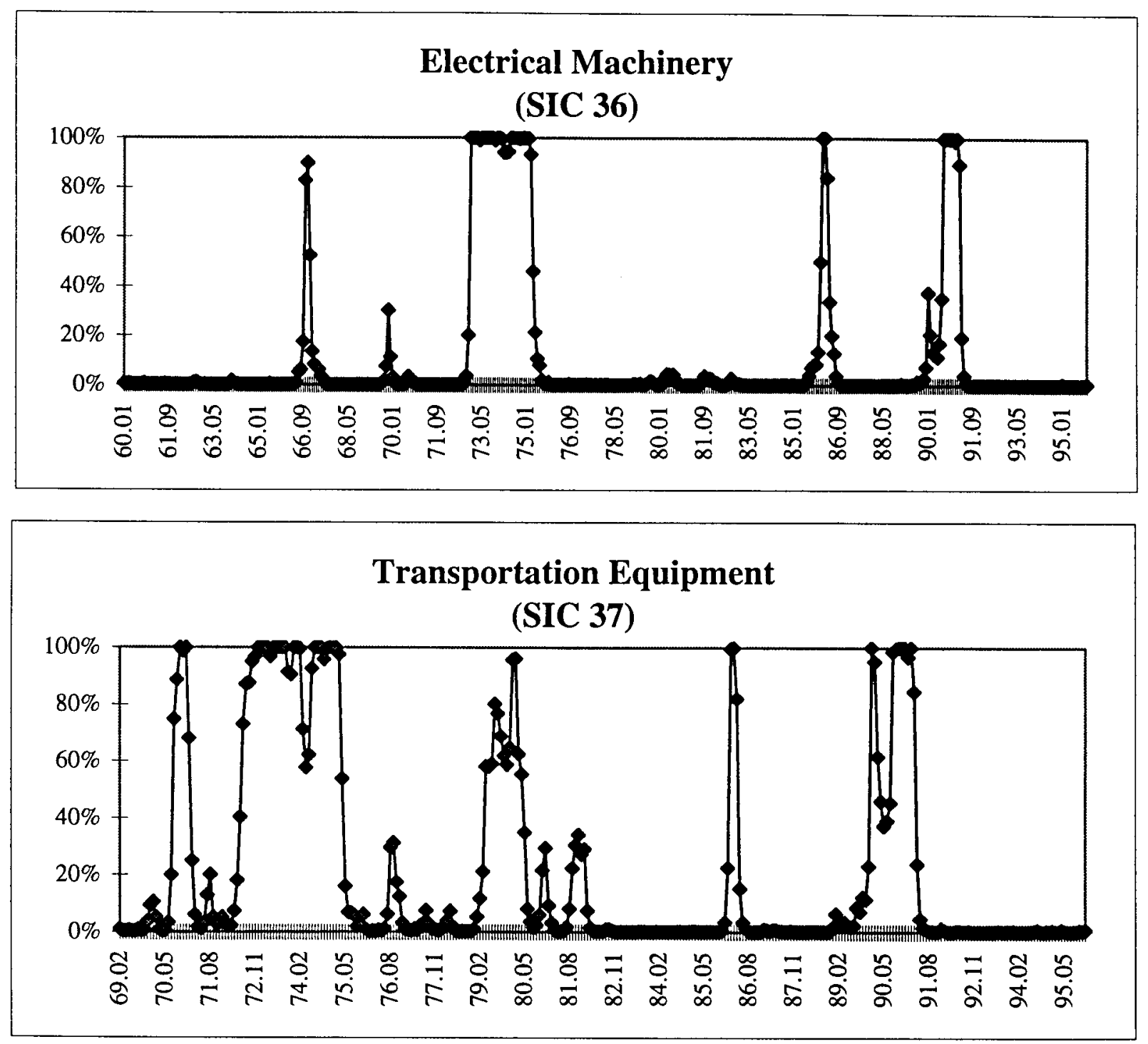


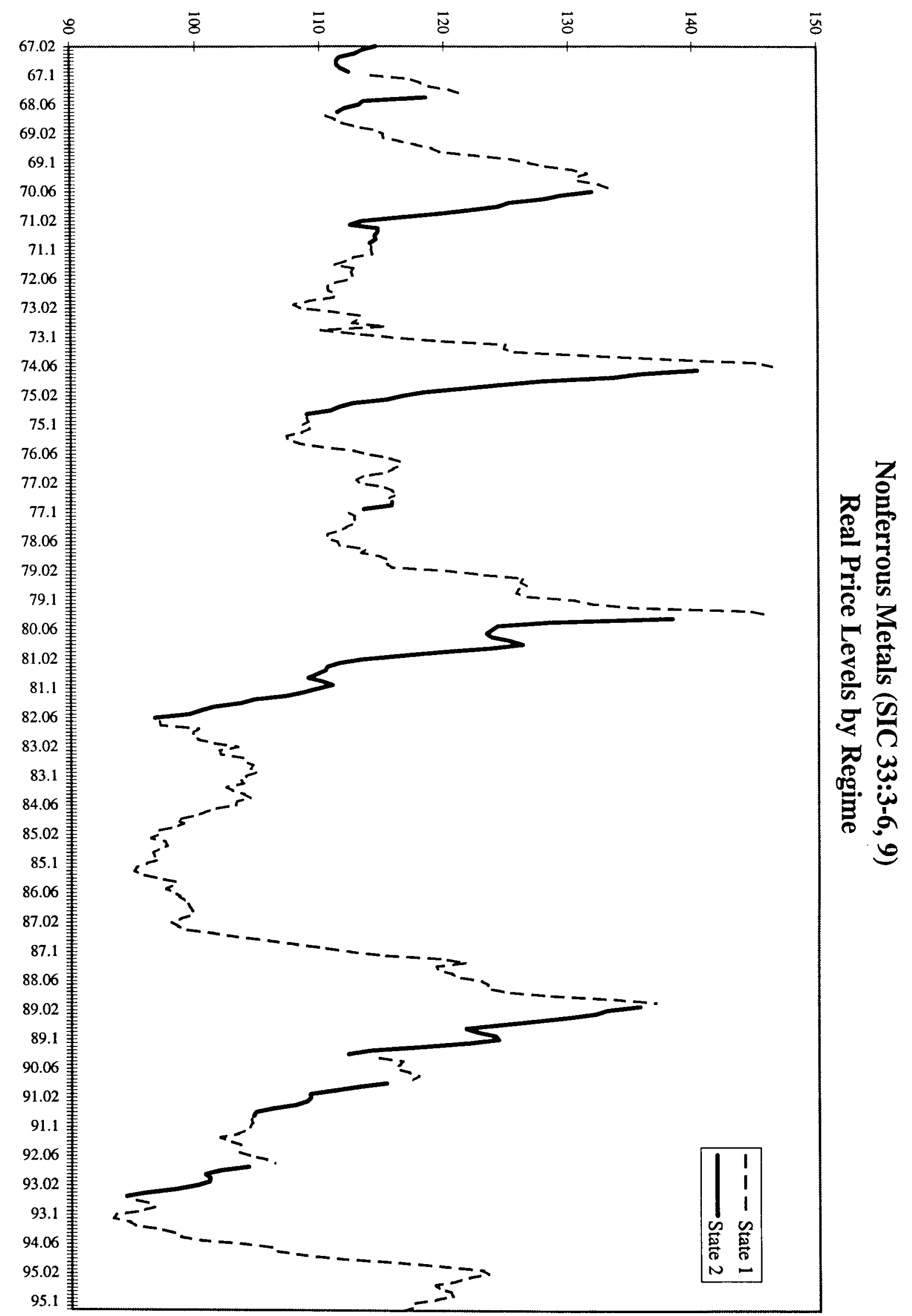

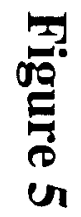


Figure 6. Relationship between Capacity Utilization in Recessions and Price Variance Ratios

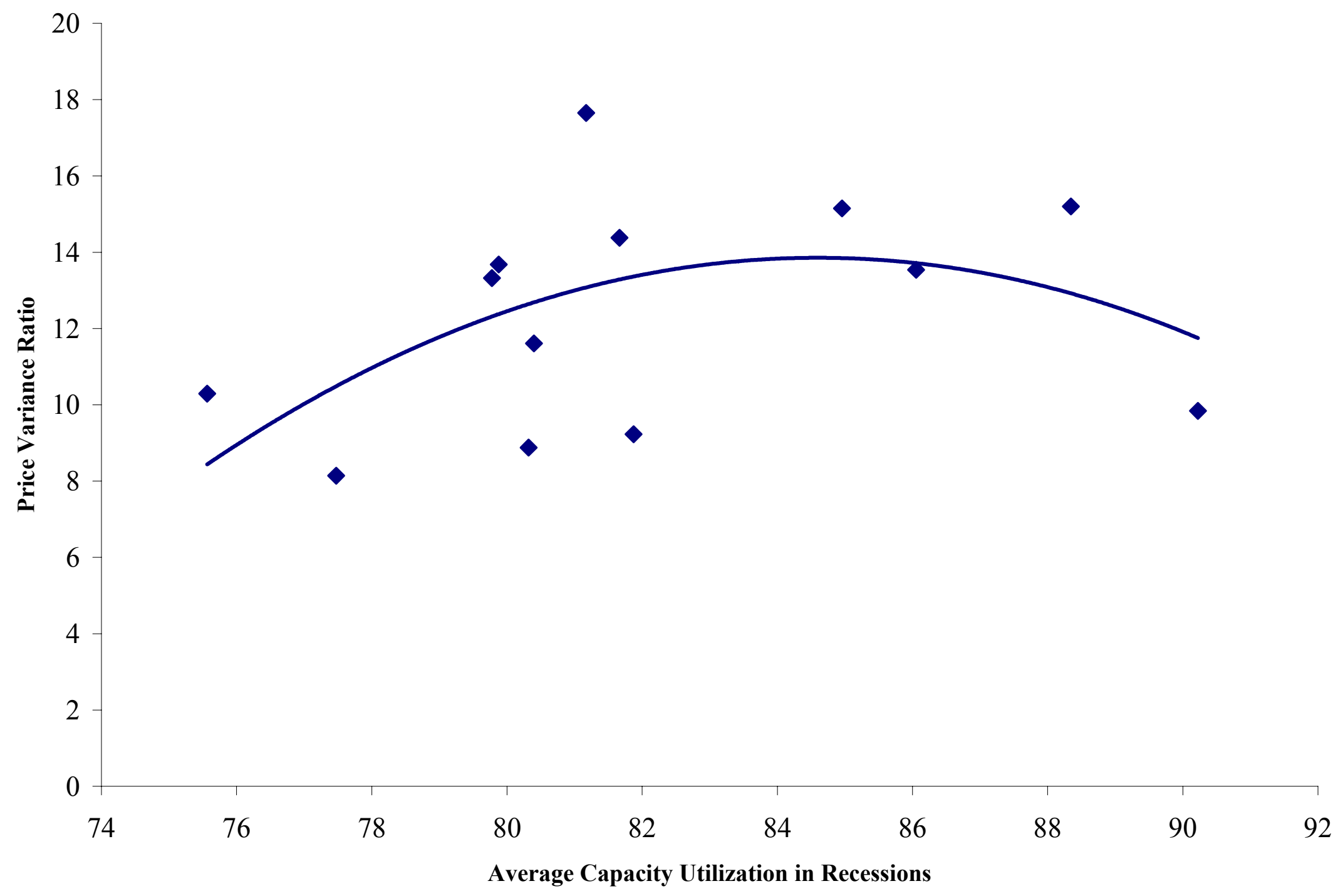


Figure 7a. Histograms of Price Changes by State
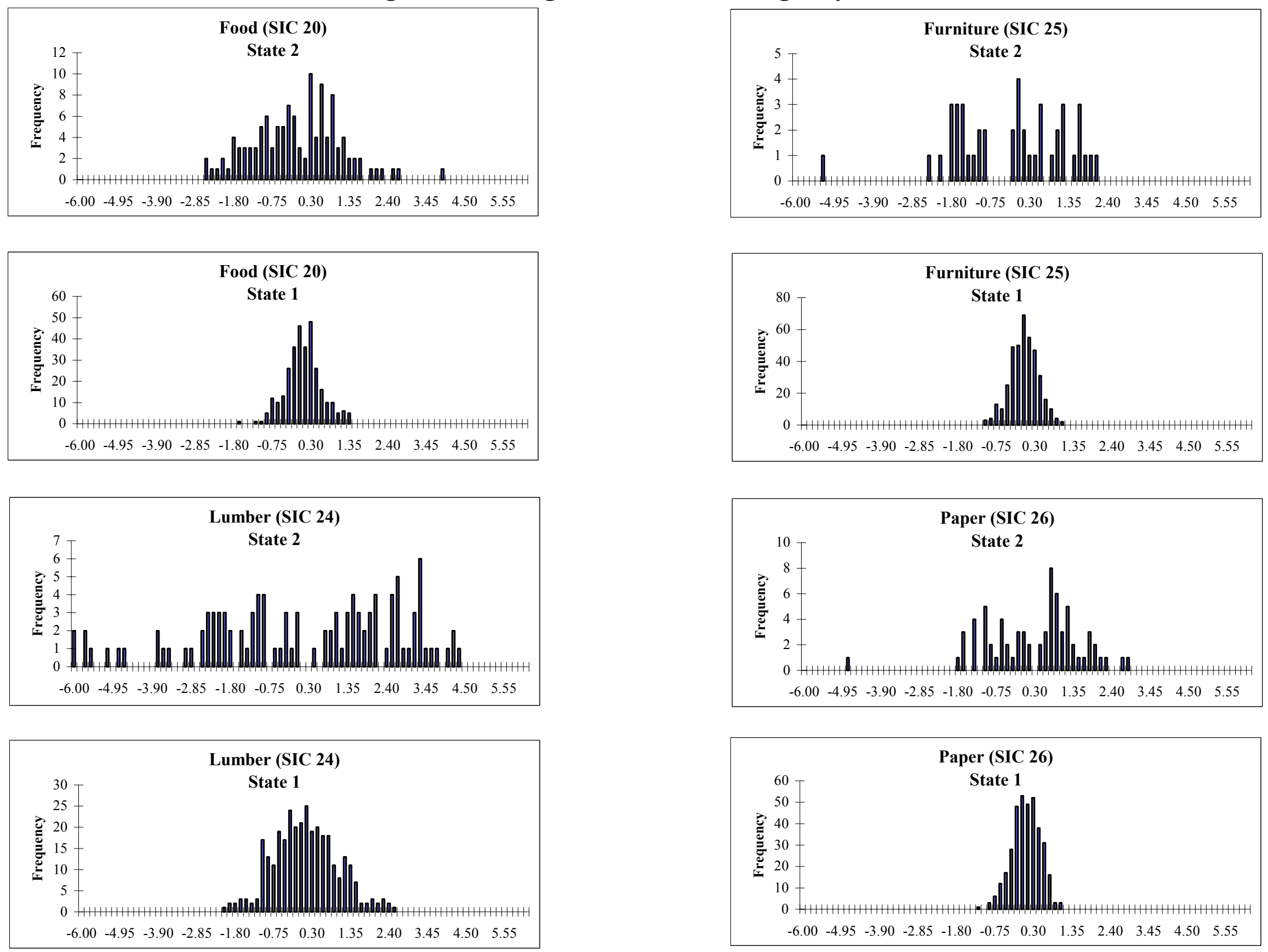
Figure 7b. Histograms of Price Changes by State
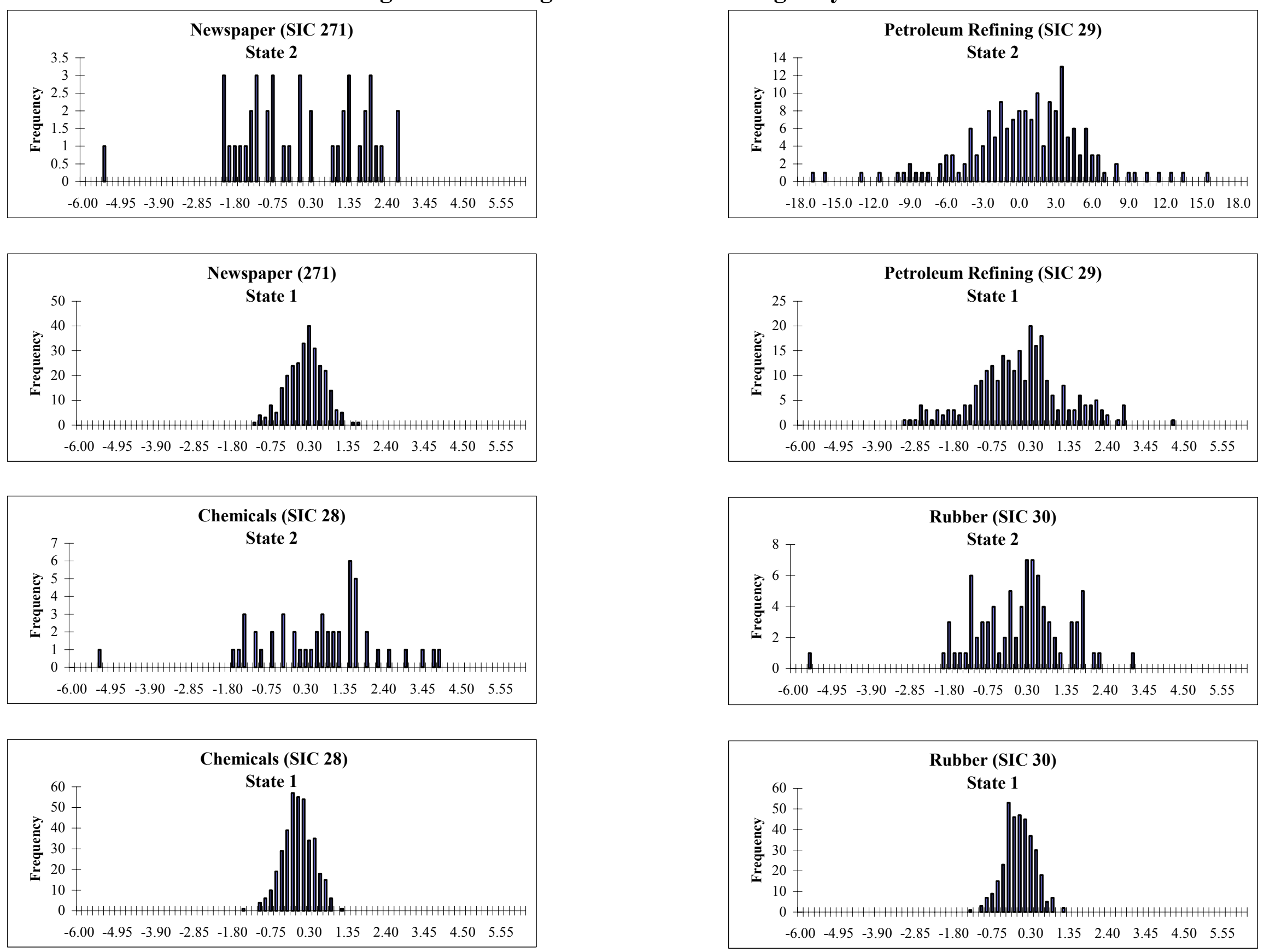
Figure 7c. Histograms of Price Changes by State
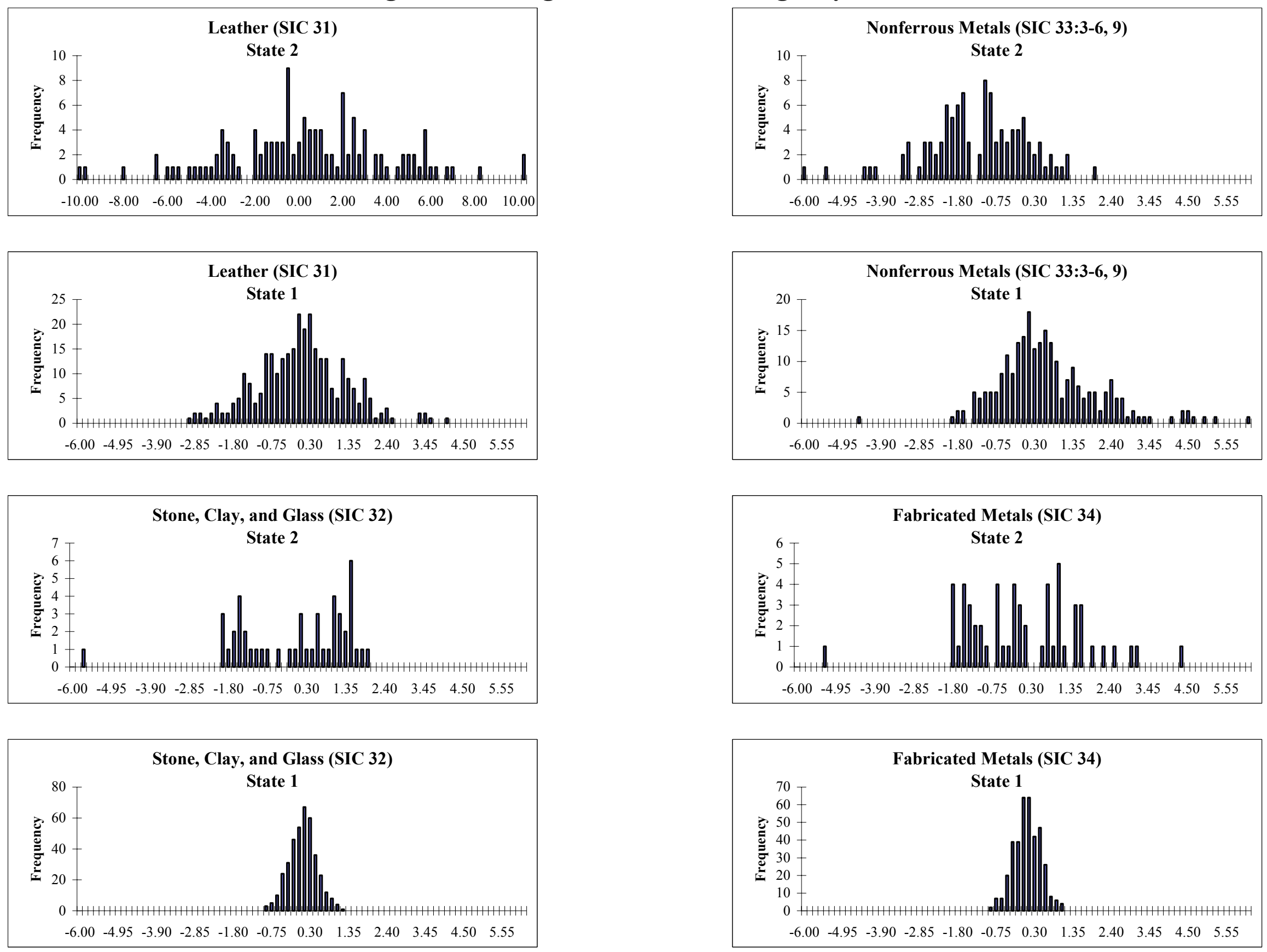
Figure 7d. Histograms of Price Changes by State
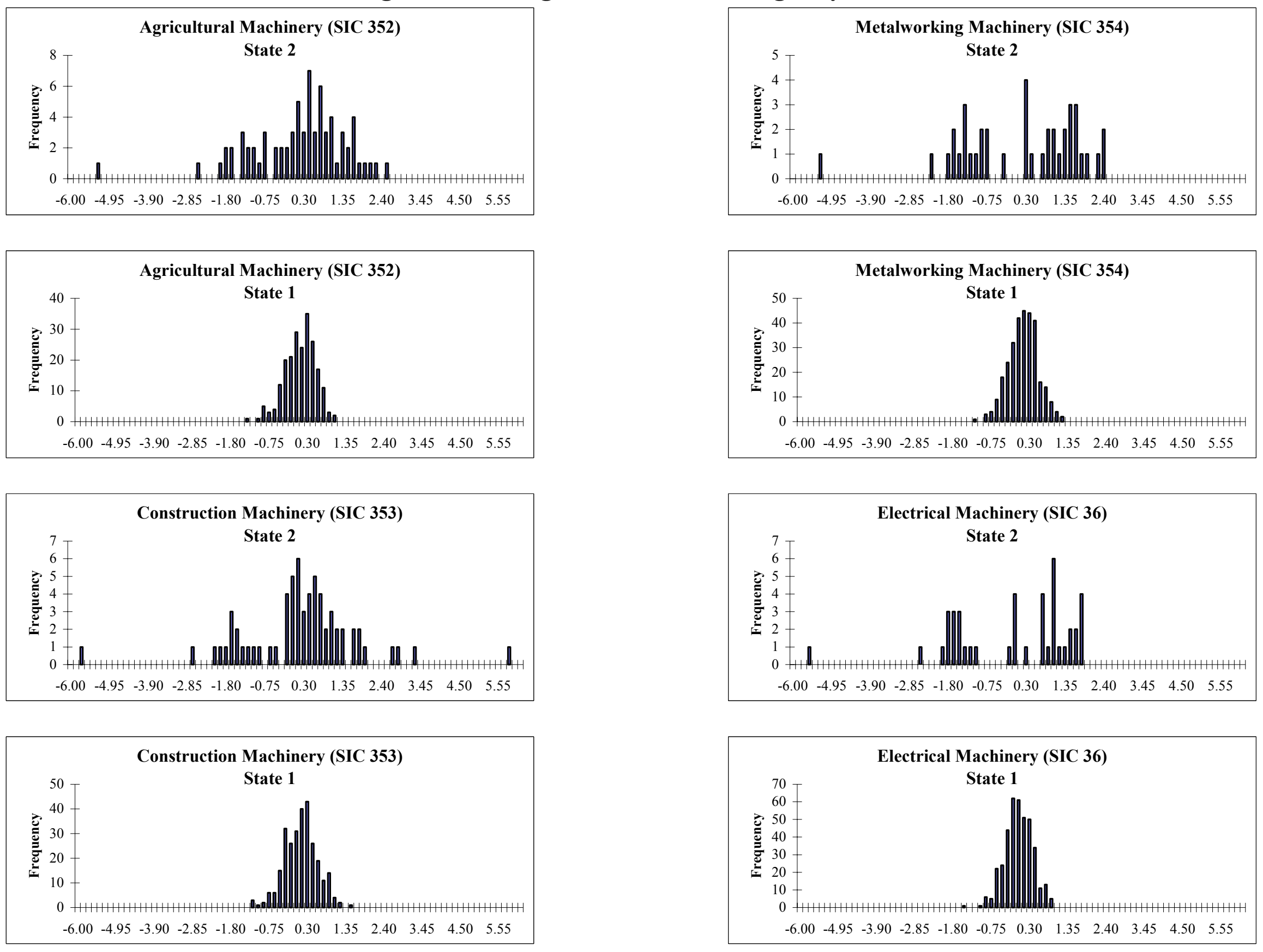
Figure 7e. Histograms of Price Changes by State
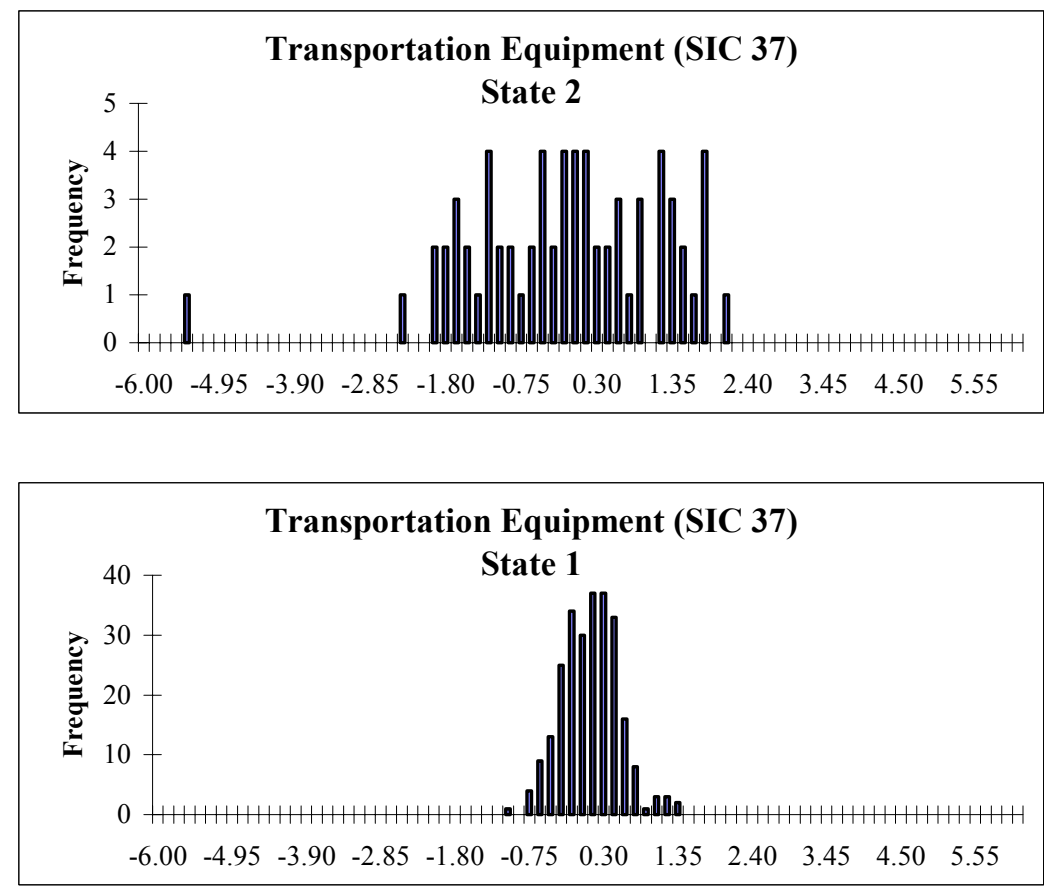